\title{
Temporal evolution of the structural properties of seasonal sea ice during the early melt season
}

\author{
Haruki ISHII, ${ }^{1}$ Takenobu TOYOTA ${ }^{2}$ \\ ${ }^{1}$ Fuji Filter Manufacturing Co. Ltd, Sakura, Japan \\ ${ }^{2}$ Institute of Low Temperature Science, Hokkaido University, Sapporo, Japan \\ E-mail: toyota@lowtem.hokudai.ac.jp
}

\begin{abstract}
During the early melt season, when sea-ice extent begins to retreat due to increasing heat absorption from the atmosphere and ocean, the sea ice becomes porous and weakens. This induces the break-up of ice floes and accelerates the melting process substantially. Determining how sea-ice structure evolves during this season is important for understanding the melting process on a global scale. We investigated this issue using field observations, laboratory experiments and numerical modeling, focusing on the effect of the C-shaped temperature profile on the internal structure of sea ice. Field observations were conducted to examine this effect on $\sim 0.3 \mathrm{~m}$ thick ice on Lake Saroma, located at the coast of Hokkaido, Japan. To test the generalization from these observational case studies, laboratory experiments were conducted using a tank with $0.12 \mathrm{~m}$ thick ice. Additionally, evolution of ice structure from winter to early spring was numerically analyzed using meteorological data. From these studies, we find that the heat convergence, caused by the C-shape temperature profile, is essential to the internal melting particularly in the upper layer. This increases the porosity of the sea ice, leading to a rapid decrease in its flexural strength during the season.
\end{abstract}

\section{INTRODUCTION}

Seasonal sea-ice regions occupy a significant fraction of the total sea-ice extent, which amounts to $50 \%\left(8.4 \times 10^{6} \mathrm{~km}^{2}\right)$ in the Arctic and $80 \%\left(15.3 \times 10^{6} \mathrm{~km}^{2}\right)$ in the Antarctic, referenced to each winter maximum (Comiso, 2010). Thus the advance and retreat of the seasonal sea-ice zone (SIZ) controls the interannual variability of the total sea-ice area and plays an important role in the atmosphere-ocean system. However, due to its complexity and the lack of observations, the retreat process is not yet well understood. Although in the SIZ the ice-ocean albedo feedback mechanism is known to be essential to the retreat of sea-ice area (e.g. Ackley and others, 2001; Nihashi and Cavalieri, 2006; Perovich and others, 2007), the precise mechanism of heat exchange between sea ice and the ocean needs closer examination. To improve the understanding of this process, the evolution of the inner structure of sea ice seems to be a key issue. With increasing temperature, sea ice becomes porous and then weakened in flexural strength, which can induce its break-up through the penetration of ocean waves (Bennetts and others, 2010; Prinsenberg and Peterson, 2011). This accelerates the melting of ice floes significantly because the heat transfer from the open water to the sea ice increases with the increasing floe perimeters (Steele, 1992; Toyota and others, 2011). The open water area produced by melting allows waves to penetrate further into the ice area, leading to further break-up. Therefore wave-ice interaction, accompanied by temporal evolution of ice structure, has a positive feedback. In this scenario, the early melt season is critical because of the rapid change in ice properties, including ice strength, at this time (Shokr and Barber, 1994; Johnston, 2006).

Although any increase in temperature will result in internal melting within the sea ice where the liquid (brine) and solid phases (pure ice) are in equilibrium with the brinedependent freezing temperature, intense melting at a certain depth may enhance the ice porosity significantly. For bare fast ice in the Antarctic, the internal absorption of solar radiation was shown to be essential for such intense internal melting to occur (e.g. Ishikawa and Kobayashi, 1985). However, since in the SIZ sea ice is usually covered with snow with high albedo (0.7-0.9), it is unlikely that this effect occurs there. Instead, we concentrate on the C-shaped vertical temperature profile in sea ice, which is often present with the increase in surface temperature during the early melt season (Petrich and Eicken, 2009). It produces a convergence of conductive heat flux within the sea ice, which contributes to the heat transfer into the lower depths and leads to intense internal melting there. Although such a temperature profile is considered to be a property peculiar to sea ice which has a thermal hysteresis caused by the coexistence of salty water and pure ice, little attention has been paid to its effect on the melting process. Recent studies suggest that this effect may contribute significantly to internal melting during the early melt season. Abe (2007) and Tison and others (2008) found evidence of intense internal melting in the 'honeycomb-like structure' at 10$20 \mathrm{~cm}$ depth within the sea ice, where temperature was locally a minimum (Fig. 1). Ackley and others (2008) used a numerical model to show that the growth of the internal 'gap' layer, which is occasionally found just below a thin solid layer of ice in late first-year and second-year Antarctic sea ice in summer (Haas and others, 2001), can be explained by a downward conductive heat flux.

Whereas the observational monitoring of internal ice properties in the growth season has been conducted by many researchers (e.g. Nakawo and Sinha, 1981), studies during the early melt season are relatively limited. From a 1 month long observation during the early melt season in Resolute Passage, Canadian Eastern Arctic, Shokr and Barber (1994) found that C-shaped temperature profiles tended to occur when the air temperature exceeded about $-5^{\circ} \mathrm{C}$ and the salinity in the top layer subsequently decreased rapidly. 


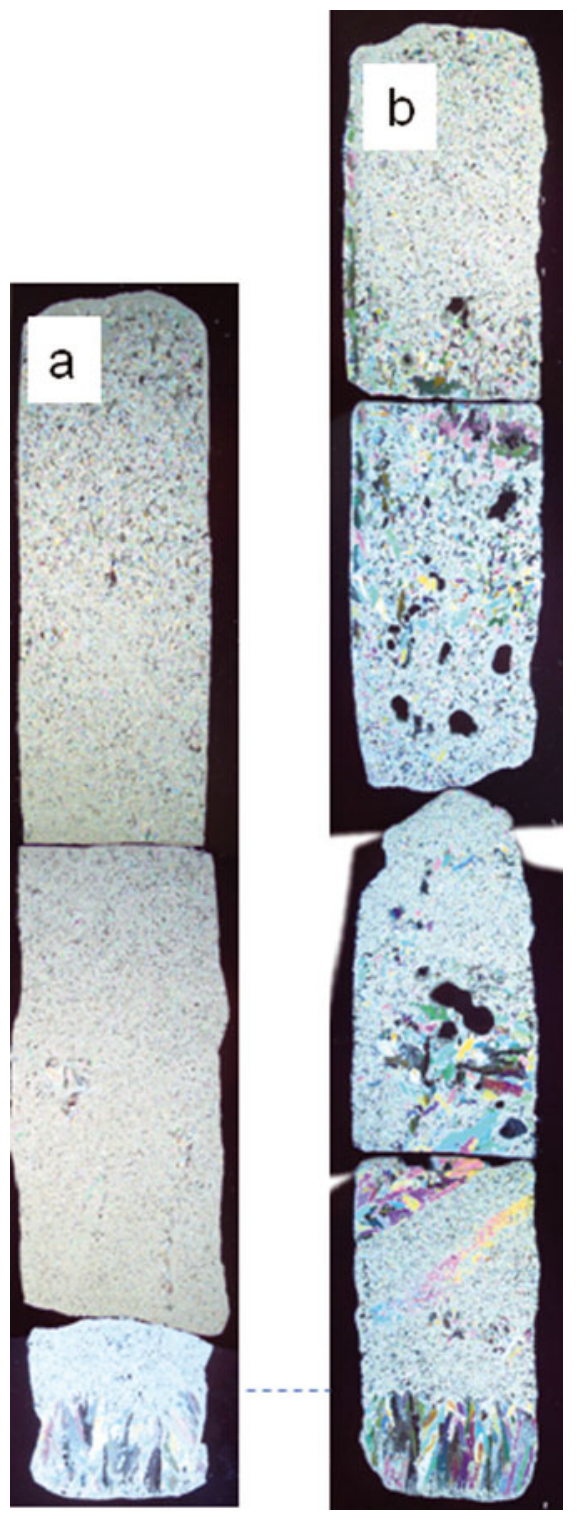

Fig. 1. Textural properties of the ice core obtained from the repeat site in Lake Saroma in (a) mid-February and (b) early March 2006, showing the evolution of a honeycomb-like structure during the early melt season. The ice thickness was 0.40 and $0.51 \mathrm{~m}$, respectively. Judging from the same length of columnar ice between the two cores, the thickness accretion seems to have been made by the snow-ice formation on top of the ice. The temperature profile had a linearly decreasing trend with depth, from -1.6 to $-3.1^{\circ} \mathrm{C}$, in mid-February and a weak C-shape with a minimum of $-0.6^{\circ} \mathrm{C}$ at $0.35 \mathrm{~cm}$ depth, as cited from Abe (2007).

From tank experiments, Kojima and others (2005) found that during the early melting stage a porous layer appeared under the ice surface that was associated with the formation of a Cshaped temperature profile. Johnston (2006) showed from the observational monitoring of first-year ice from winter to summer in the Arctic and sub-Arctic that a rapid decrease in ice strength occurred in association with the increase of brine volume fraction when the C-shaped temperature profile appeared. Tison and others (2008) examined the temporal evolution of the structural ice properties on the Weddell Sea first-year ice during the melting season and suggested that the intense internal melting in the upper part of ice occurred with the increase of surface temperature. All these studies suggest that a C-shaped temperature profile

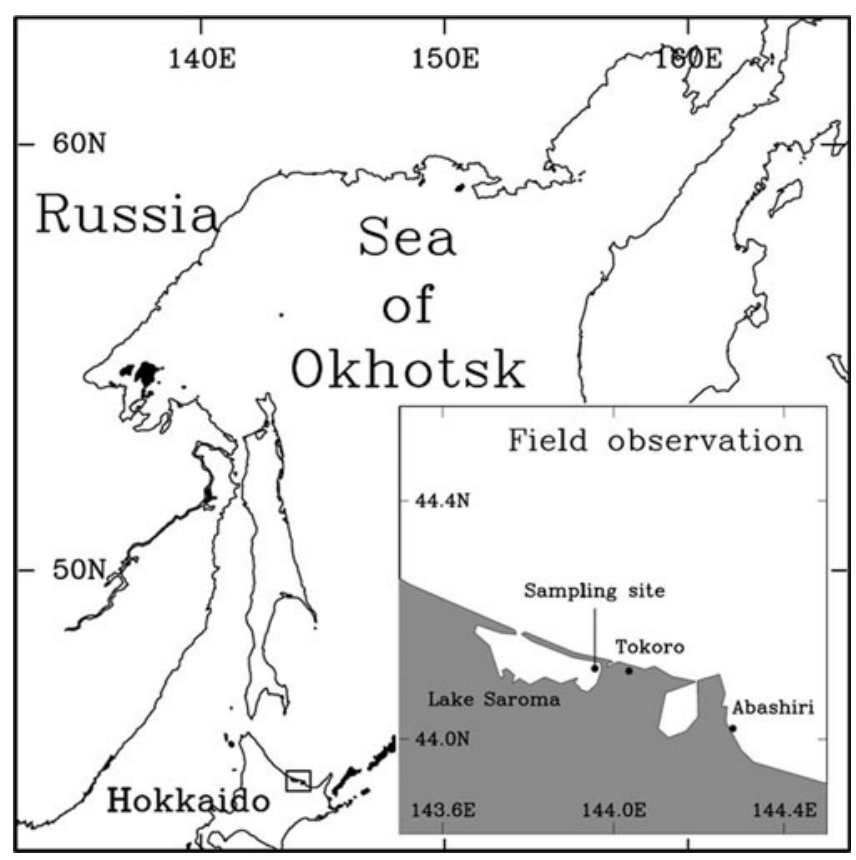

Fig. 2. Map of Lake Saroma and the sampling location. The locations of the Japan Meteorological Agency meteorological stations at Tokoro and Abashiri are also shown.

during the early melt season is closely related to intense internal melting, especially in the upper layer of the ice, and may induce a rapid decrease in strength. However, an estimation of the conductive heat flux associated with a C-shaped temperature profile has not been done in detail, so its effect on internal melting is not yet fully understood.

The objective of this study is to examine the effect of the convergence of conductive heat flux on the internal melting, in relation to the temporal evolution of internal structure, from field observations, tank experiments and numerical calculations, and to characterize the ice properties during the early melt season. In the field observations, the role of conductive heat flux in the heat budget was determined for actual in situ sea ice. For the tank experiment, the time series of conductive heat flux was examined in more detail for $12 \mathrm{~cm}$ thick ice, relating it to the temporal evolution of the internal structure of the ice. Finally we extend these results back to real sea ice $\sim 0.4 \mathrm{~m}$ thick by analyzing the time series of ice properties with meteorological data from late winter to spring.

\section{FIELD OBSERVATION}

The observational field program was conducted on Lake Saroma, located at the northeastern coast of Hokkaido, Japan, in February 2009 (Fig. 2). Lake Saroma has an area of $150.35 \mathrm{~km}^{2}$ with a mean water depth of $8.7 \mathrm{~m}$ and is connected to the Sea of Okhotsk through two inlets, which makes it a brackish water lake with salinity ranging from 5 to 33 psu. The lake is normally completely covered with sea ice from late January to early April, the maximum thickness reaching $\sim 0.4 \mathrm{~m}$ (Shirasawa and others, 2002). It is level landfast first-year ice with no developed ridges. These conditions provide a stable site suitable for investigating the evolution of sea-ice structure in winter. Another notable feature of the lake is the large variation of water level, amounting to $\sim 0.7 \mathrm{~m}$, due to tidal effects. 
The sampling site was located at $44.12^{\circ} \mathrm{N}, 143.97^{\circ} \mathrm{E}$ in the eastern part of the lake, where ice thickness, snow depth, water depth and sea-water salinity were approximately $0.30 \mathrm{~m}, 0.06 \mathrm{~m}, 0.8 \mathrm{~m}$ and $32 \mathrm{psu}$, respectively (Fig. 2). The sampling date was 20 February 2009, corresponding to late winter, and the ice was sampled at nearly 3 hourly intervals (06:00, 09:00, 12:30, 15:30 and 18:30 local standard time (LST)). The weather was cloudy during the day, and air temperature ranged from -6 to $-2{ }^{\circ} \mathrm{C}$. Although our initial plan was to conduct the monitoring observation until midMarch (early spring), the stormy weather accompanied by heavy snowfall on 21 February caused the site to deteriorate significantly and prevented us from continuing the observation. Accordingly, the study was refocused on diurnal variation rather than seasonal evolution. Nevertheless, since the C-shaped temperature profile appeared around the top layer of ice in the daytime, we expect that the thermodynamic properties relating to the early melt season can be obtained from the single day of observations.

\section{Data and methods}

To examine the effect of snow, we collected two kinds of ice core at each sampling time, with the exception of the 06:00 sampling: one on the snow-covered area (natural conditions) and the other on the nearby bare ice area $(2 \mathrm{~m} \times 2 \mathrm{~m})$ which was made by removing snow on ice at 06:00. Immediately after removing an ice core, ice temperatures were measured by drilling holes into the cores and inserting a thermistor probe with accuracy $0.1 \mathrm{~K}$ at an interval of $0.05 \mathrm{~m}$ to obtain a vertical temperature profile. Snow temperature was measured with the same thermistor at an interval of $0.03 \mathrm{~m}$. To estimate the surface heat budget, the short- and longwave radiative flux was monitored on the intact snow area $\sim 3 \mathrm{~m}$ away from the sampling site with a radiometer (EKO, MR-40) with an accuracy of $2 \%$ at an interval of $1 \mathrm{~min}$. Air temperature and humidity were monitored at the radiometer site at a height of $0.5 \mathrm{~m}$ above the snow surface. The collected ice and snow samples were transferred to the cold room $\left(-16^{\circ} \mathrm{C}\right)$ after the observation and kept there until ready for analysis. In the cold room, each ice core was split lengthwise into two pieces: one was used for the thin- and thick-section analysis, while the other was cut into a vertical section and segmented every $0.05 \mathrm{~m}$ to obtain vertical profiles of density, salinity, brine volume fraction, and $\delta^{18} \mathrm{O}$. The ice density was determined from the weight and dimensions of each segment with an estimated accuracy of $\sim 1 \%$. The $\delta^{18} \mathrm{O}$ and salinity were measured for the melted ice segment with a mass spectrometer (DELTA plus) and a salinometer (TOWA Electronic Industry, Model SAT-210), respectively. The accuracy was $0.02 \%$ for $\delta^{18} \mathrm{O}$ and $<0.05 \mathrm{psu}$ for salinity. The brine volume fraction was calculated with ice temperature, density and salinity from the formula of Cox and Weeks (1983). Thin $(<1 \mathrm{~mm})$ and thick $(5 \mathrm{~mm})$ sections were analyzed to observe the crystallographic alignments with crossed polaroids and the structure of inclusions with scattered light, respectively.

\section{Heat budget calculation}

Using the in situ measurements, the heat budget at the surface and inner ice layers was calculated with a thermodynamic ice model similar to Maykut and Untersteiner (1971, hereafter referred to as M\&U) and the following assumptions:
1. Vertical heat transport is predominant.

2. The bottom of the sea ice is kept at the freezing point of sea water $\left(-1.8^{\circ} \mathrm{C}\right)$.

3. A flux toward (away from) the surface is taken to be positive (negative).

In the calculation, the 3 hourly ice and snow temperatures were interpolated onto an hourly grid, and the hourly heat budgets were estimated for the snow layer and each $5 \mathrm{~cm}$ thick layer of sea ice from the following equations:

for the snow layer,

$\mathrm{FQ}=\mathrm{FSW}\left[1-\exp \left(-\mu_{\mathrm{s}} h_{\mathrm{s}}\right)\right]+\mathrm{FLW}+\mathrm{FSH}+\mathrm{FLH}+\mathrm{FCl} ;$

for the top layer of bare ice,

$\mathrm{FQ}=\mathrm{FSW}\left[1-\exp \left(-\mu_{\mathrm{si}} h\right)\right]+\mathrm{FLW}+\mathrm{FSH}+\mathrm{FLH}+\mathrm{FCl}$

and for the other layers in sea ice,

$$
\begin{aligned}
\mathrm{FQ}= & \mathrm{FSW}\left[\exp \left(-\mu_{\mathrm{si}} z\right)-\exp \left(-\mu_{\mathrm{si}}\{z+h\}\right)\right] \\
& +k_{\mathrm{si}}\left[\left(\frac{\partial T}{\partial z}\right)_{\text {lower }}-\left(\frac{\partial T}{\partial z}\right)_{\text {upper }}\right]
\end{aligned}
$$

where FSW, FLW, FSH, FLH and FCl are the net shortwave radiation, net longwave radiation, sensible heat flux, latent heat flux and conductive heat flux at the surface, respectively. $\mu_{\mathrm{s}}, \mu_{\mathrm{si}}, T, k_{\mathrm{si}}, h$ and $z$ are the extinction coefficients of snow and sea ice, temperature, thermal conductivity of sea ice, layer thickness $(5 \mathrm{~cm})$ and depth, respectively. For the FSW, the observed values (FSW $\downarrow-$ FSW $\uparrow$ ) were used for snow-covered ice while FSW $\downarrow(1-\alpha)$ was given for bare ice, where $\alpha$ is the surface albedo of bare ice and set to 0.5 (Perovich, 1998). $\mu_{\mathrm{s}}$ and $\mu_{\mathrm{si}}$ are set to be $20 \mathrm{~m}^{-1}$ (Mellor, 1977) and $3 \mathrm{~m}^{-1}$, respectively (Maykut, 1986). For the FLW, the observed values were used for both snow-covered ice and bare ice because the difference in the surface conditions has little effect on FLW $\uparrow$. FSH and FLH were calculated by the bulk method. FSH was given by $\rho C_{p} C_{\mathrm{s}} u\left(T_{\mathrm{a}}-T_{\mathrm{s}}\right)$, where $T_{\mathrm{a}}$ is the observed air temperature, $\rho$ is the air density $\left(1.3 \mathrm{~kg} \mathrm{~m}^{-3}\right)$, $C_{p}$ is the specific heat of the air $\left(1004 \mathrm{~J} \mathrm{~kg}^{-1} \mathrm{~K}^{-1}\right), C_{\mathrm{s}}$ is the transfer coefficient for sensible heat and $u$ is the observed wind speed. FLH was given by $0.622 \rho L_{V} C_{\mathrm{e}} u\left(r e_{\mathrm{sa}}-e_{\mathrm{sS}}\right) / p$, where $L_{V}$ is the latent heat of sublimation $\left(2.84 \times 10^{6} \mathrm{~J} \mathrm{~kg}^{-1}\right.$; Yen, 1981), $C_{\mathrm{e}}$ is the transfer coefficient for latent heat, $r$ is the observed relative humidity, $p$ is the surface pressure and $e_{\mathrm{sa}}$ and $e_{s s}$ are the saturated vapor pressure in the atmosphere and at the surface, respectively. The dependence of $e_{\mathrm{s}}$ on air temperature is expressed as a fourth-order polynomial developed by Maykut (1978). The values of $p$ and $u$ were obtained from the nearest automatic weather station (run by the Japan Meteorological Agency (JMA)) at Tokoro, located $\sim 5 \mathrm{~km}$ away from Lake Saroma (Fig. 2). $C_{\mathrm{s}}$ and $C_{\mathrm{e}}$ were taken to be $1.37 \times 10^{-3}$ after Andreas and Makshtas (1985) on the assumption of neutral stability of the air in the atmospheric boundary layer. $\mathrm{FCl}$ was calculated from $-k(\partial T / \partial z)$, where the thermal conductivity $k$ was calculated from $k_{\mathrm{s}}=2.22362\left(\rho_{\mathrm{s}}\right)^{1.885}\left(\mathrm{~W} \mathrm{~m}^{-1} \mathrm{~K}^{-1}\right)$ for snow (Yen, 1981) and from the empirical formula, $k_{\mathrm{si}}$, given as a function of the thermal conductivity of brine and pure ice including air bubbles by Yen (1981) for sea ice.

To estimate the degree of internal melting which has progressed from the initial state in each layer, we introduced 

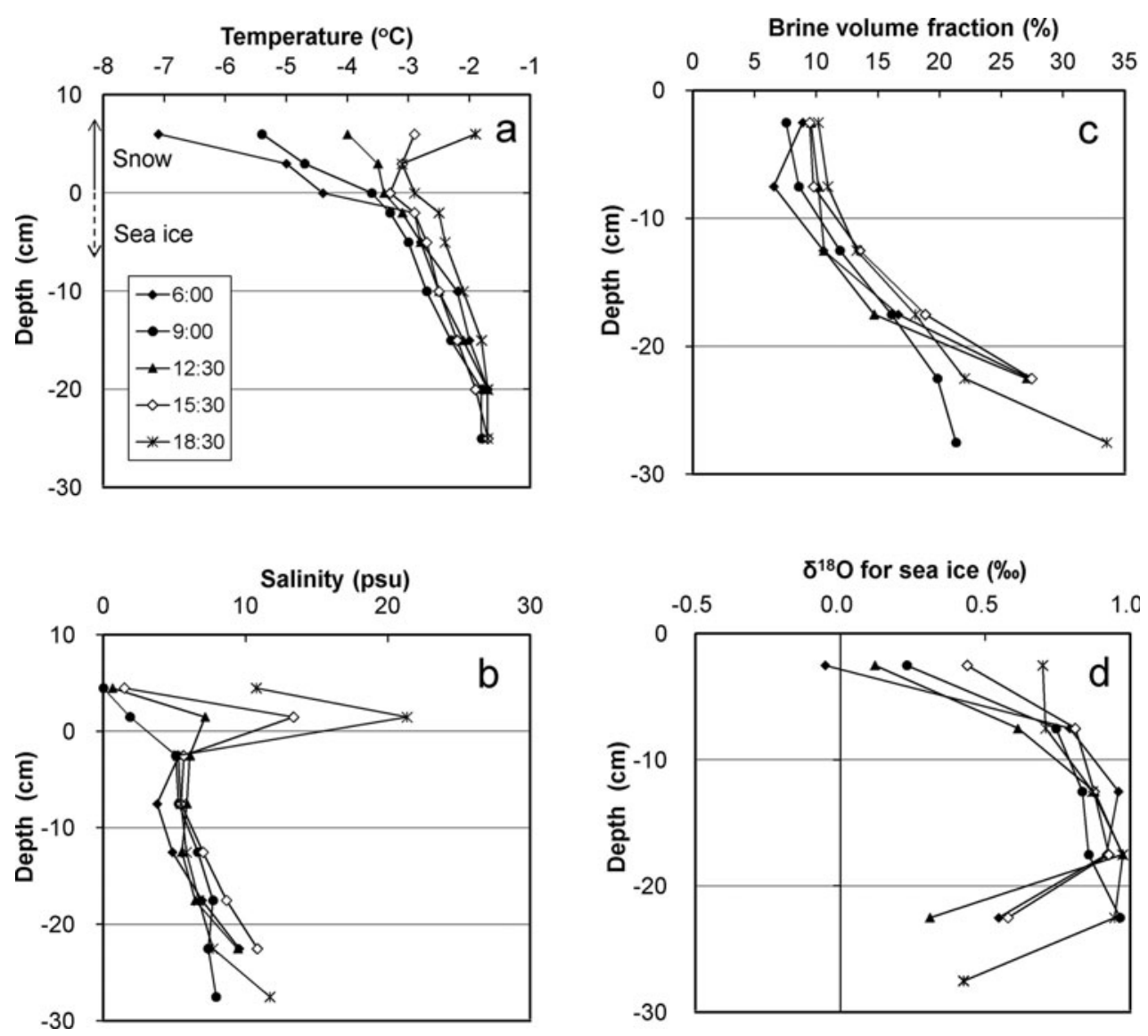

Fig. 3. Temporal evolution of the vertical profiles of (a) temperature, (b) salinity, (c) brine volume fraction and (d) $\delta^{18} \mathrm{O}$ for snow-covered ice, observed in Lake Saroma on 20 February 2009.

the following parameter as a melt progression index:

$$
\operatorname{MPI}(t)=\frac{\int_{0}^{t} F Q \mathrm{~d} t}{Q M_{\mathrm{si}}} \times 100[\%],
$$

where FQ is given by Eqns (1), (2) or (3), and $Q$ and $M_{\mathrm{si}}$ are the specific latent heat of fusion and the mass of sea ice at each level, respectively. $Q$ is given by (Ono, 1968):

$$
\begin{aligned}
Q= & \left(333.6-2.114 T-0.1143 S_{\mathrm{i}}+18.05 \frac{S_{\mathrm{i}}}{T}\right. \\
& \left.+0.00335 S_{\mathrm{i}} T-0.00377 T^{2}\right) \times 10^{3}\left[\mathrm{~J} \mathrm{~kg}^{-1}\right]
\end{aligned}
$$

where $S_{\mathrm{i}}$ and $T$ are salinity (psu) and temperature $\left({ }^{\circ} \mathrm{C}\right.$ ) of sea ice at the initial state. The denominator of Eqn (4) is the total heat required to melt the entire mass, while the numerator is the heat storage accumulated from the initial state. The reason for defining this parameter was to reduce the bias of the ice conditions at the initial stage and examine the intense internal melting layer explicitly. Because $Q$ tends to have a larger value when the temperature is lower at the initial stage, the summation of FQ is not necessarily a good indicator of the progress of internal melting with respect to ice strength.

\section{Results and discussion}

For snow-covered ice, the temporal evolution of the vertical profiles of temperature, salinity, brine volume fraction and $\delta^{18} \mathrm{O}$ are shown in Figure 3. Figure 3a shows that whereas a snow layer with low heat capacity and thermal conductivity protected the underlying ice layer from significant warming, the temperature in the snow layer increased significantly and eventually produced a C-shaped profile in the afternoon. In Figure $3 \mathrm{~b}$, the prominent increase of salinity in the snow layer during daytime is attributed to the infiltration of tidewater flooding through some cracks (high tide occurred there at 11:05 with amplitude of $\sim 0.3 \mathrm{~m}$ ). The slight increase of ice temperature and salinity resulted in some increase in brine volume fraction throughout (Fig. 3c). Since the brine volume fraction ranged from $5 \%$ to $>20 \%$ and was always above the threshold of permeability ( $5 \%$; Golden and others, 1998), the brine network in the sea ice seemed to be permeable. Thin-section analysis with the $\delta^{18} \mathrm{O}$ data showed that all layers of the sea ice were composed of granular ice originating from sea water.

Based on these data, the individual heat flux was calculated for each ice layer. The time series of $\mathrm{FQ}, \mathrm{FCl}$ and FSW show that at all levels the temporal evolution of FQ $\left(-30\right.$ to $\left.50 \mathrm{~W} \mathrm{~m}^{-2}\right)$ was governed by $\mathrm{FCl}\left(-30\right.$ to $\left.50 \mathrm{~W} \mathrm{~m}^{-2}\right)$, and FSW (less than a few $\mathrm{W} \mathrm{m}^{-2}$ ) had little effect. Neither net longwave radiation nor turbulent heat flux at the surface (mostly less than $\pm 10 \mathrm{~W} \mathrm{~m}^{-2}$ ) had a significant effect on $\mathrm{FQ}$. The result obtained in the $0-5 \mathrm{~cm}$ layer, where the internal melting occurred, is shown in Figure 4. Here the downward $\mathrm{FCl}$ essentially controlled the heat-flux convergence FQ. As FQ began to increase at 13:00, MPI also increased significantly in this layer. This result indicates that the temperature profile, especially the positive gradient near the surface, is the controlling factor for the internal melting of sea ice. 


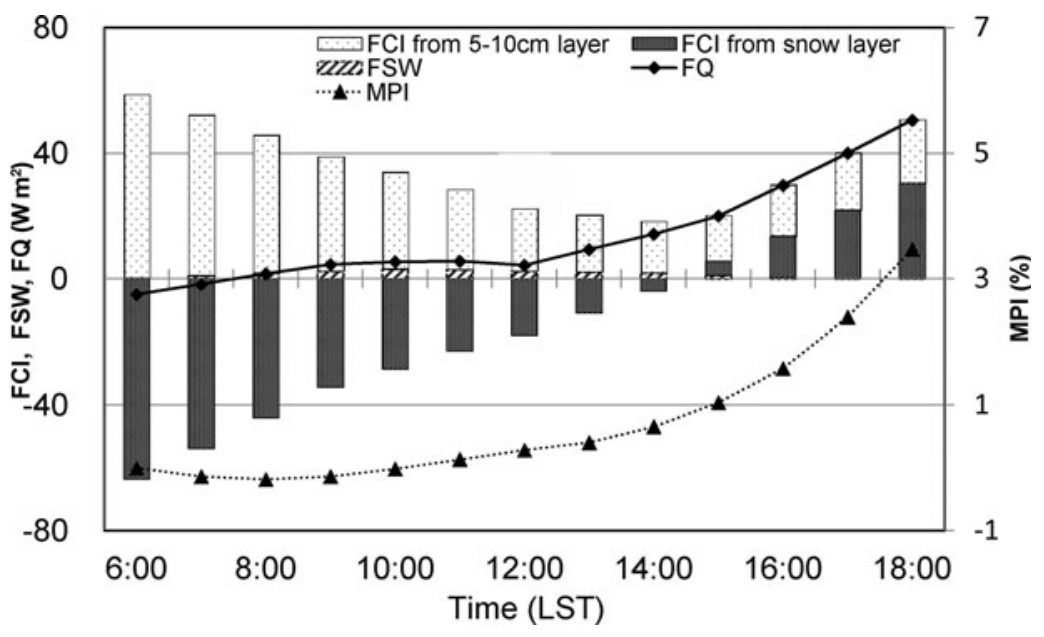

Fig. 4. Time series of FQ, FCI, FSW and MPI at the $0-5 \mathrm{~cm}$ layer for snow-covered ice, estimated from the observational results in Figure 3.

Intense internal melting in the $0-5 \mathrm{~cm}$ layer is evidenced in the evolution of the $\delta^{18} \mathrm{O}$ profiles. Figure $3 \mathrm{~d}$ shows a significant increase of $\delta^{18} \mathrm{O}$ by $0.8 \%$ in the top layer $(0$ $5 \mathrm{~cm}$ ) after MPI increased. Since pure ice has a higher $\delta^{18} \mathrm{O}$ value $(>0 \%)$ than either sea water $(-1.25 \%$ ) or snow $(<-5 \%)$ due to isotopic fractionation during freezing and there is no fractionation on pure ice melting (Jouzel and Souchez, 1982), the increase in $\delta^{18} \mathrm{O}$ indicates that the brine in sea ice was replaced by the meltwater from pure ice, as suggested by Tison and others (2008). Besides, it was shown from the thin-section analysis that the mean grain size in the $0-5 \mathrm{~cm}$ layer increased from $0.9 \mathrm{~mm}$ at $06: 00$ to $1.4 \mathrm{~mm}$ at $18: 30$, whereas it remained almost the same in the other layers. This enlargement of grain size may be explained by the refreezing of partially melted grains while the ice core was kept in the cold room.

For bare ice, the temporal evolution of the vertical profiles of temperature, salinity, brine volume fraction and $\delta^{18} \mathrm{O}$ is shown in Figure 5. Figure 5a and b show a more prominent increase of both temperature and salinity in sea ice compared with those for snow-covered ice. The temperature increase can be explained by the penetration
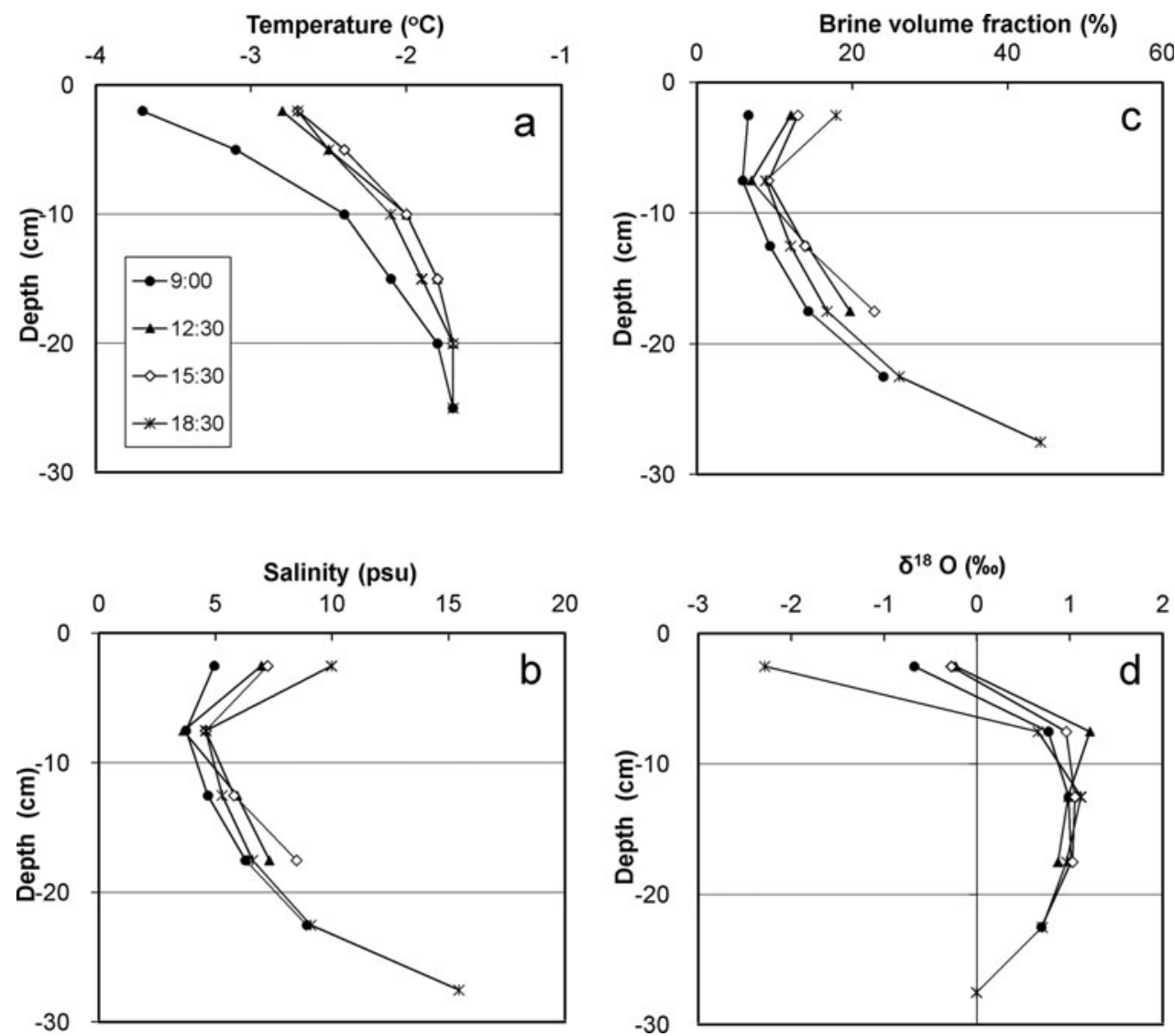

Fig. 5. Temporal evolution of the vertical profiles of (a) temperature, (b) salinity, (c) brine volume fraction and (d) $\delta^{18} \mathrm{O}$ for bare ice, observed in Lake Saroma on 20 February 2009. 


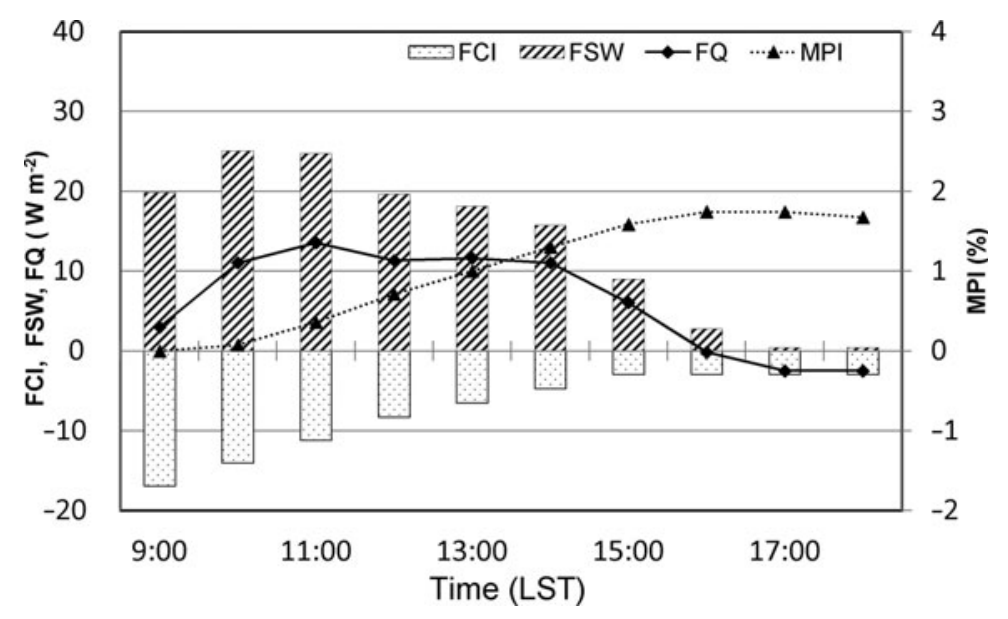

Fig. 6. Time series of FQ, FCl, FSW and MPI in the $5-10 \mathrm{~cm}$ layer for bare ice, estimated from the observational results in Figure 5 .

of solar radiation, as is shown later, while the salinity increase seems to have been caused by tidewater flooding in the daytime. It is likely that in the absence of snow, flooded sea water infiltrated directly into the underlying ice from the surface. In addition, the increase in porosity in the top layer (Fig. 5c) might have favored infiltration. This also explains the significant decrease in $\delta^{18} \mathrm{O}$ in the $0-10 \mathrm{~cm}$ layer, in contrast to the case of snow-covered ice (Fig. $5 \mathrm{~d}$ ).

The calculated heat flux shows that FQ had the highest value in the $0-5 \mathrm{~cm}$ layer $\left(30-50 \mathrm{~W} \mathrm{~m}^{-2}\right)$, followed by that in the $5-10 \mathrm{~cm}$ layer $\left(0-15 \mathrm{~W} \mathrm{~m}^{-2}\right)$ and in the deeper layers $\left(-5\right.$ to $\left.+10 \mathrm{~W} \mathrm{~m}^{-2}\right)$. Accordingly, $\mathrm{MPI}$ in the $0-5 \mathrm{~cm}$ layer increased from $0 \%$ at 09:00 to $7.5 \%$ at $18: 00$. We note that in this layer the contribution of FSW $\left(30-40 \mathrm{~W} \mathrm{~m}^{-2}\right)$ to FQ (20-60 W $\mathrm{m}^{-2}$ ) was comparable with or slightly larger than

\section{Copper-constantan thermocouples}
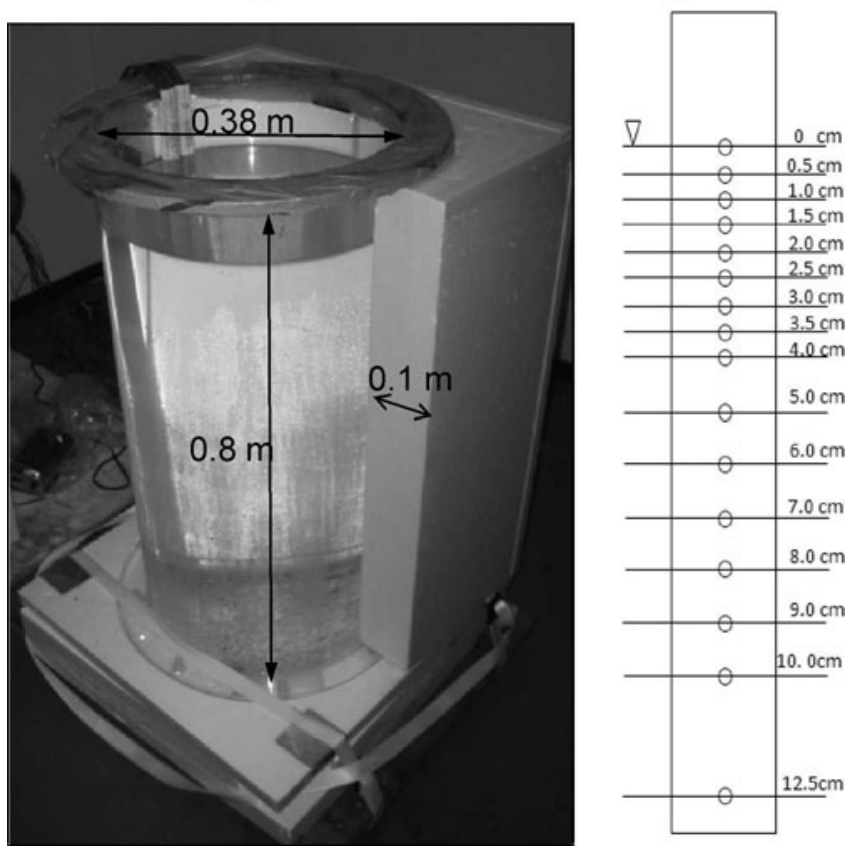

Fig. 7. Apparatus of the tank experiment. The tank was covered with $0.1 \mathrm{~m}$ thick Styrofoam to avoid freezing at the side wall and bottom. The copper-constantan thermocouples were mounted on the side wall to monitor the temperature profile. The right-hand panel shows the measurement depths. that of $\mathrm{FCl}\left(20-40 \mathrm{~W} \mathrm{~m}^{-2}\right)$ in the daytime, as indicated by previous results (e.g. Ishikawa and Kobayashi, 1985). The net longwave radiation and turbulent heat fluxes contributed to slightly cooling the surface layer $\left(-10\right.$ to $\left.0 \mathrm{~W} \mathrm{~m}^{-2}\right)$. To contrast FSW with $\mathrm{FCl}$ in the inner layer, the time series of $\mathrm{FCl}$ and $\mathrm{FSW}$ in the $5-10 \mathrm{~cm}$ layer are shown with FQ and MPI (Fig. 6). FCl made a negative contribution to FQ in this layer. Therefore, as FSW diminished, FQ was gradually reduced and eventually became negative in the late afternoon. The evolution of MPI was mostly dependent on FSW and increased from $0 \%$ at 09:00 to $\sim 2 \%$ at 18:00.

Thus it was shown from the heat budget analysis of the field observation that for snow-covered ice the convergence of $\mathrm{FCl}$ is essential to the internal melting, especially near the ice surface, in contrast to the case of bare ice.

\section{LABORATORY EXPERIMENT}

In the previous section, the conductive heat flux was shown to be essential to the intense internal melting, particularly near the surface for snow-covered ice. In the field observations, however, the temperature measurement was coarse in both time and spacing since the temperature varied rapidly and took a nonlinear profile near the surface (Fig. 3a). To estimate the evolution of conductive heat flux more precisely, the monitoring of more detailed temperature profiles, especially near the surface, is required. For this purpose, we conducted a laboratory experiment as the next step. In the experiment, we first grew sea ice within a tank filled with natural sea water up to $0.12 \mathrm{~m}$ thick at a room temperature of $-18^{\circ} \mathrm{C}$, and then raised the room temperature to $5^{\circ} \mathrm{C}$ to examine how the ice structure evolved with time, relating it to the temperature profile and hence the conductive heat flux. To focus on the effect of the conductive heat flux, we did not use either snow or sunlight. Ideally the sea ice would be grown up to $\sim 0.3 \mathrm{~m}$ which was observed in the field observation. However, we had to stop the freezing when the thickness reached $\sim 0.1 \mathrm{~m}$ to minimize the effect of the increase of sea-water salinity caused by seaice formation on the growth conditions, i.e. the freezing point. This is a limitation of the tank experiment. Even so, we believe the result is applicable to sea ice in nature as far as the melting process at the early stage is concerned, because, as shown later, the temperature rises first at the surface and gradually shifts to the inner level. 

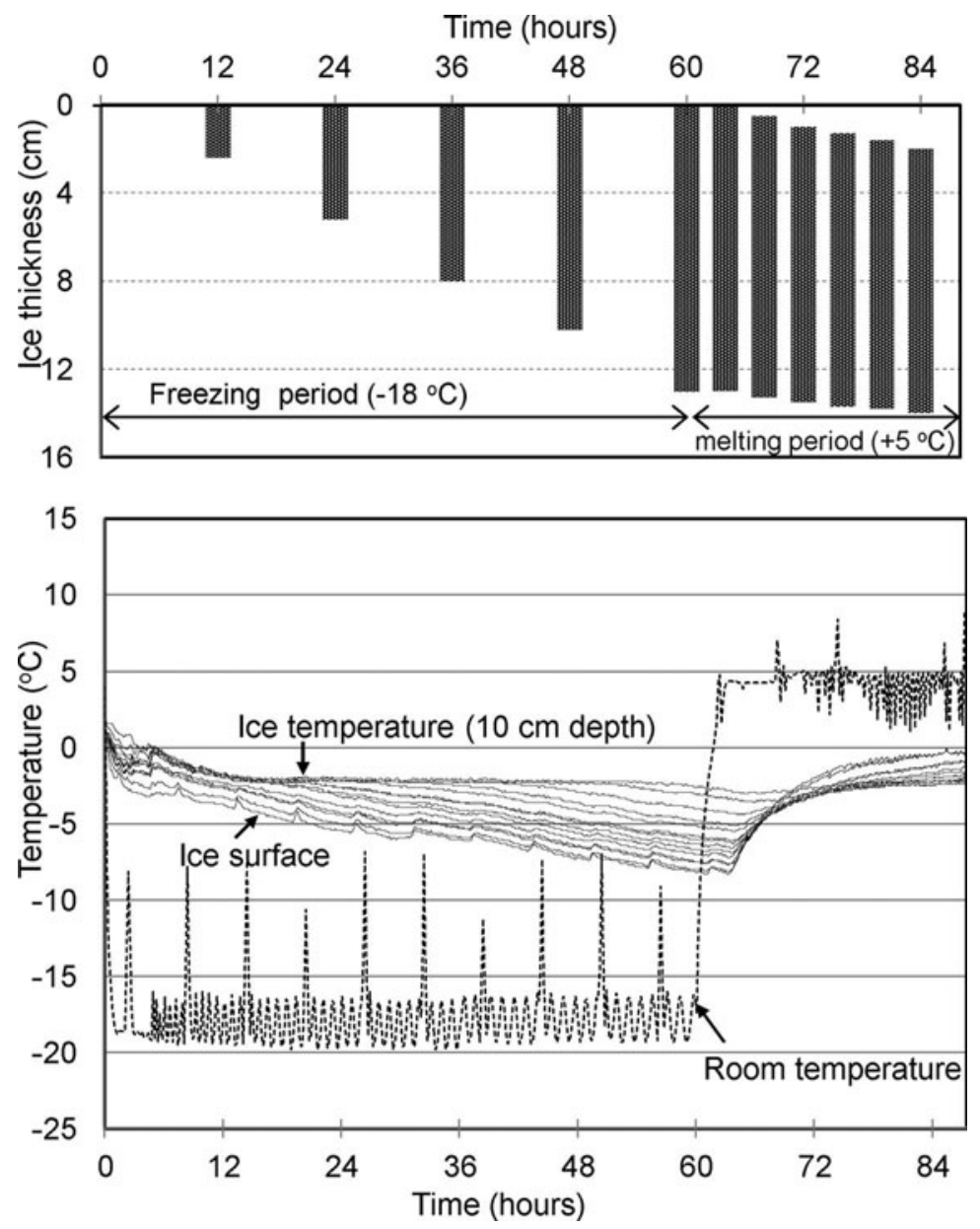

Fig. 8. Time series of ice thickness and ice temperature at each depth during the experiment. The depths of ice temperature are $0.0,0.5,1.0$, $1.5,2.0,2.5,3.0,3.5,4.0,5.0,6.0,7.0,9.0$ and $10.0 \mathrm{~cm}$ from the ice surface.

\section{Apparatus and experimental procedure}

We prepared a thermally insulated cylinder tank (inner dimensions of $0.38 \mathrm{~m}$ diameter and $0.80 \mathrm{~m}$ height) and filled it with natural sea water collected from the Sea of Okhotsk (32.5 psu) to $0.75 \mathrm{~m}$ depth (Fig. 7). The tank, made from a transparent acrylic, is $0.01 \mathrm{~m}$ thick and covered with a $0.1 \mathrm{~m}$ thick layer of Styrofoam (except the upper surface) to avoid the freezing on the side wall and the bottom. In order to monitor the ice/water temperature, we prepared copperconstantan thermocouples and mounted them on the side wall at vertical intervals of $0.5 \mathrm{~cm}$ for the $0-4 \mathrm{~cm}$ layer from the water surface, $1.0 \mathrm{~cm}$ for the $4-10 \mathrm{~cm}$ layer, and $2.5 \mathrm{~cm}$ for the $10-25 \mathrm{~cm}$ layer. The room temperature was monitored on top of the tank with another thermometer. These temperature data were logged at 1 min intervals. In order to monitor the sea-water salinity, we made a small hole on a side wall of the tank at $0.4 \mathrm{~m}$ depth and stuffed it with a rubber stopper, through which water samples were taken carefully with an injector. As for ice thickness, a measuring scale was put on the side wall and the thickness was measured visually. Water sampling and ice thickness measurement were conducted together at intervals of 6 hours during freezing and 4 hours during melting.

Before starting this experiment, the tank was cooled uniformly to a room temperature of $-1{ }^{\circ} \mathrm{C}$ in a cold room, with the water occasionally stirred. After the water temperature settled down to the near freezing point, we set the room temperature at $-18^{\circ} \mathrm{C}$ and began to grow sea ice. When the ice thickness reached $\sim 0.12 \mathrm{~m}$, we raised the room temperature to $5^{\circ} \mathrm{C}$ (hereafter referred to as the melt onset) and examined the evolution of temperature profiles and textural structure until 36 hours after the melt onset (hereafter we refer to the time $x x$ hours after the melt onset as $T x x$ ). In order to see the evolution of ice structure, we cut out a rectangular ice block with a basal area of $0.2 \mathrm{~m} \times 0.2 \mathrm{~m}$ using a portable saw. Since the condition in the tank was significantly disturbed once the block was removed, we needed to repeat the same experiment seven times under the same conditions to collect the ice blocks at T00, T04, T08, T12, T16, T20 and T24.

Immediately after collecting the ice block, we transferred it to another cold room of $-16^{\circ} \mathrm{C}$ and divided it into four sections with a basal area of $0.1 \mathrm{~m} \times 0.1 \mathrm{~m}$ : one was used for thick/thin-section analysis to see the textural structure, two for the measurement of ice density, salinity and $\delta^{18} \mathrm{O}$, and the last one was archived. Among these procedures, thicksection analysis was done first to minimize the refreezing of melted water. The other sections were kept in the cold room until ready for analysis. The method of analysis for ice density, salinity and $\delta^{18} \mathrm{O}$ is the same as that described in the previous section except that the vertical resolution was set to $0.02 \mathrm{~m}$. The vertical profile was determined by taking the average of the result obtained from the two sections. With temperature, salinity and density data, brine volume fraction was calculated using the formula of Cox and Weeks (1983) at each depth. Flexural strength, $\sigma_{\mathrm{f}}$, was calculated with the 

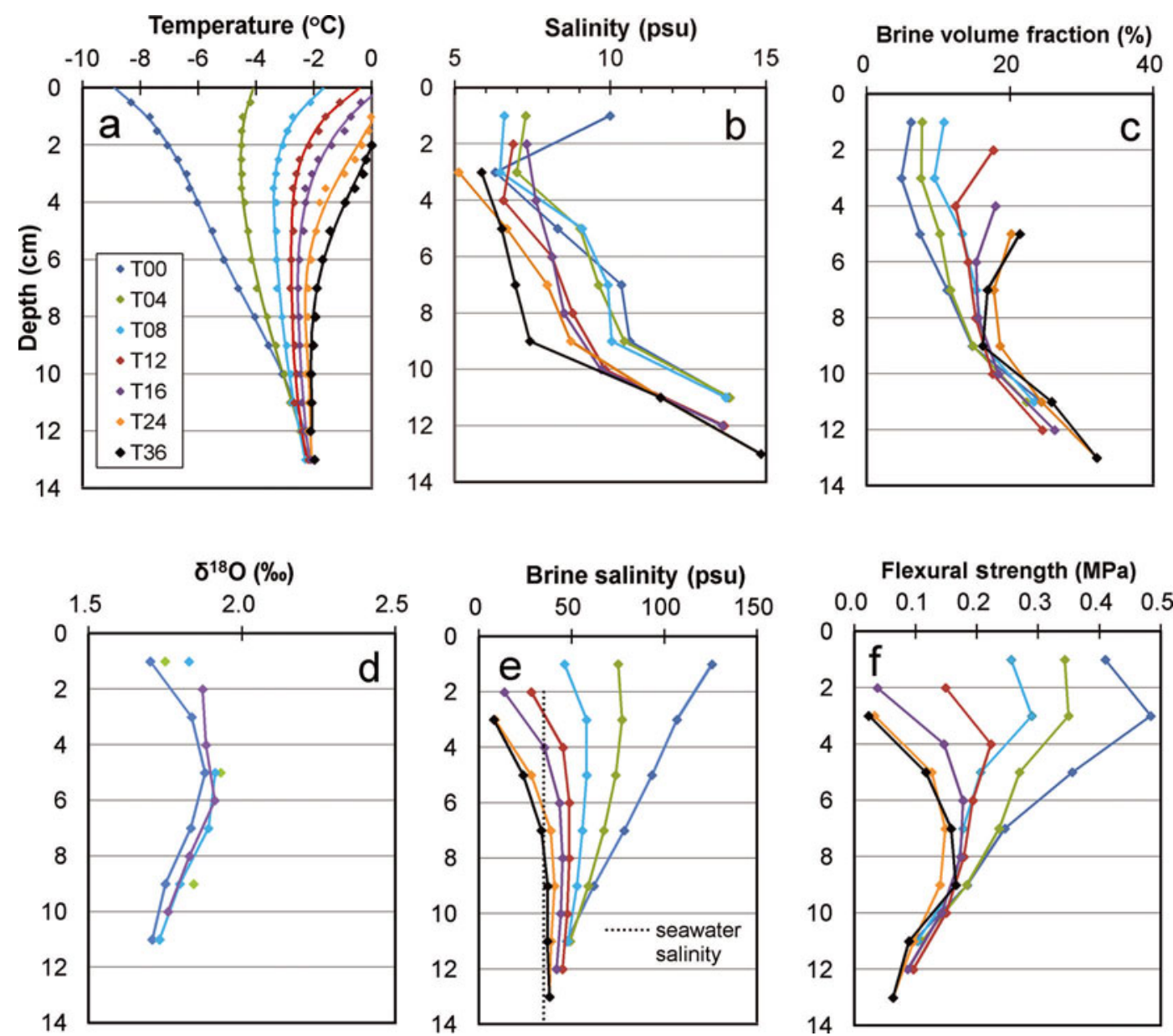

Fig. 9. Evolution of the vertical profiles after the melt onset during the experiment for (a) temperature, (b) salinity, (c) brine volume fraction, (d) $\delta^{18} \mathrm{O}$, (e) brine salinity and (f) flexural ice strength. Note that $\delta^{18} \mathrm{O}$ is represented by the difference from the initial value of $\delta^{18} \mathrm{O}$ of sea water because it varied due to fractionation by repeating the experiments.

brine volume fraction using (Timco and O'Brien, 1994):

$$
\sigma_{\mathrm{f}}=1.76 \exp \left(-5.88 \sqrt{\nu_{\mathrm{b}}}\right) .
$$

The heat budget, FQ, within the sea ice was estimated every minute at each $1 \mathrm{~cm}$ thick layer from

$$
\mathrm{FQ}=\left(k_{\mathrm{si}} \frac{\partial T}{\partial z}\right)_{\text {lower }}-\left(k_{\mathrm{si}} \frac{\partial T}{\partial z}\right)_{\text {upper }}\left[\mathrm{W} \mathrm{m}^{-2}\right],
$$

where $k_{\mathrm{si}}$ is the thermal conductivity given as a function of temperature and salinity by Yen (1981), and $\partial T / \partial z$ was calculated from the temperature profile approximated by the fifth-order regression of $T$ with respect to $z$, fitted to the observed data with a least-square method. Since $k_{\mathrm{si}}$ was estimated to be almost constant $\left(\sim 2.0 \mathrm{~W} \mathrm{~m}^{-1} \mathrm{~K}^{-1}\right)$ during the experiment, it had minimal impact on the result.

\section{Results and discussion}

The time series of ice thickness and temperature over the course of the experiment are shown in Figure 8. Both the thickness and sea-water salinity increased almost linearly with time during freezing. It took 60 hours until the ice thickness got to $0.12 \mathrm{~m}$, corresponding to a growth rate of $5 \mathrm{~cm} \mathrm{~d}^{-1}$. The salinity increase was $4.5 \mathrm{psu}$ (from $32.5 \mathrm{psu}$ to $37 \mathrm{psu})$, corresponding to a decrease in the freezing point only by $0.2^{\circ} \mathrm{C}$. Figure 8 shows the fluctuation in room temperature caused by the mechanism of the air-conditioning system, which had an amplitude of $1.5^{\circ} \mathrm{C}$ and a $20 \mathrm{~min}$ period. However, since the observed ice temperature varied on a much longer timescale, it is unlikely that this fluctuation significantly affected the ice structure. Surface ablation began to occur at T08 and it amounted to $\sim 2 \mathrm{~cm}$ by the end of the experiment. A bottom accretion of $\sim 1 \mathrm{~cm}$ occurred even after the melt onset.

Figure 9 shows the evolution of the profiles of temperature, salinity, brine volume fraction, $\delta^{18} \mathrm{O}$, brine salinity and flexural strength in sea ice after the melt onset. Brine salinity, $S_{\mathrm{b}}(\mathrm{psu})$, was calculated from

$$
S_{\mathrm{b}}=1000 \times\left(1-\frac{54.11}{T_{\mathrm{i}}}\right)^{-1}
$$

(Frankenstein and Garner, 1967), where $T_{\mathrm{i}}$ is ice temperature $\left({ }^{\circ} \mathrm{C}\right)$. The characteristic of the temperature profile in Figure $9 \mathrm{a}$ is such that with the increase of the surface temperature, the temperature gradient near the surface became positive. Nonetheless, since a negative temperature gradient was maintained near the bottom, a C-shaped profile was produced until T12. Such a temperature profile (i.e. conductive heat flux) explains the slight bottom accretion even after the melt onset (Fig. 8). This phenomenon is attributed to thermal hysteresis peculiar to sea ice which has been previously observed in Arctic perennial ice during the melt season (e.g. Perovich and others, 1997).

The evolution of the salinity profile progressed in three stages (Fig. 9b). Initially, it took a C-shape typical of first-year 
ice. At the first stage, with the increase in surface temperature, the salinity in the $0-4 \mathrm{~cm}$ layer decreased significantly while the salinity in the $4-12 \mathrm{~cm}$ layer was nearly stable until T08. At the second stage, the salinity in the $4-12 \mathrm{~cm}$ layer decreased significantly while the salinity in the $0-4 \mathrm{~cm}$ layer remained almost unchanged at T12. At the third stage, the salinity in the $2-6 \mathrm{~cm}$ layer decreased slightly while the salinity in the $6-12 \mathrm{~cm}$ layer was almost stable at T24. It is probable that the decrease in salinity in the upper layer was affected by the percolation of the melted water produced at the surface (Fig. 8).

These stages can be explained by the evolution of the brine volume fraction (Fig. 9c) and brine salinity (Fig. 9e) profiles. Initially the brine salinity profile had a linearly increasing trend with depth, indicating a potential density instability within the brine network. With the increase of brine volume near the surface, the brine network was interconnected at the $0-4 \mathrm{~cm}$ layer, which favored the highsalinity brine flowing down through the network to $\sim 4 \mathrm{~cm}$ depth. At this stage, the brine density profile was still somewhat unstable (Fig. 9e). At the second stage the brine volume fraction at the lower depth also increased enough for the high-salinity brine water to drain to the underlying sea water, which promoted the desalinization in the lower part of ice. At the third stage the brine density profile became stable, so the desalinization rate slowed down. This result is consistent with that of Tison and others (2008).

This process is also related to the evolution of flexural strength determined by the brine volume fraction (Fig. 9f). During the first and second stages when the desalinization was due to the surface melting, the flexural strength decreased at a relatively high rate. However, at the third stage after the desalinization had settled, the decreasing rate of flexural strength slowed down.

Next we examine the evolution of internal melting from the heat budget calculation. Figure 10a shows the evolution of FQ until T36. At a very early stage (T02), the local maximum appeared at $4 \mathrm{~cm}$ depth when the C-shaped profile was produced. However, as the surface temperature increased rapidly after T04, the maximum FQ shifted to the surface. With the subsequent increase in MPI at the surface, the surface ablation progressed for the period T08-T16 (Fig. 10b). Then, with an increase in the subsurface temperature, the maximum FQ migrated from the surface to the inner depth. This was $5 \mathrm{~cm}$ at T24 and $6 \mathrm{~cm}$ at T36 (Fig. 10a), and the MPI gradually increased in the inner depth as well (Fig. 10b).

The result of heat budget calculation is supported by the evolution of $\delta^{18} \mathrm{O}$ profiles and the thick-section analysis. In Figure 9d, a significant increase in $\delta^{18} \mathrm{O}$ is found at the upper $4 \mathrm{~cm}$ until T16 when a large value of FQ was estimated near the surface. It is likely that brine with lower $\delta^{18} \mathrm{O}$ was replaced by meltwater from pure ice, with higher $\delta^{18} \mathrm{O}$ associated with gravity drainage of brine, as shown in the field observations. During the same period, it was shown from the thick-section analysis that the porous structure at $2 \mathrm{~cm}$ depth became prominent (Fig. 11). Afterwards at T24, when the maximum FQ shifted downward, the porous structure also migrated to the lower depth, which is consistent with the fact that MPI increased significantly up to $\sim 40 \%$ at $5 \mathrm{~cm}$ depth.

These results indicate that the conductive heat flux is a controlling factor of internal melting and the estimation of FQ and MPI coincided with the evolution of the inner ice
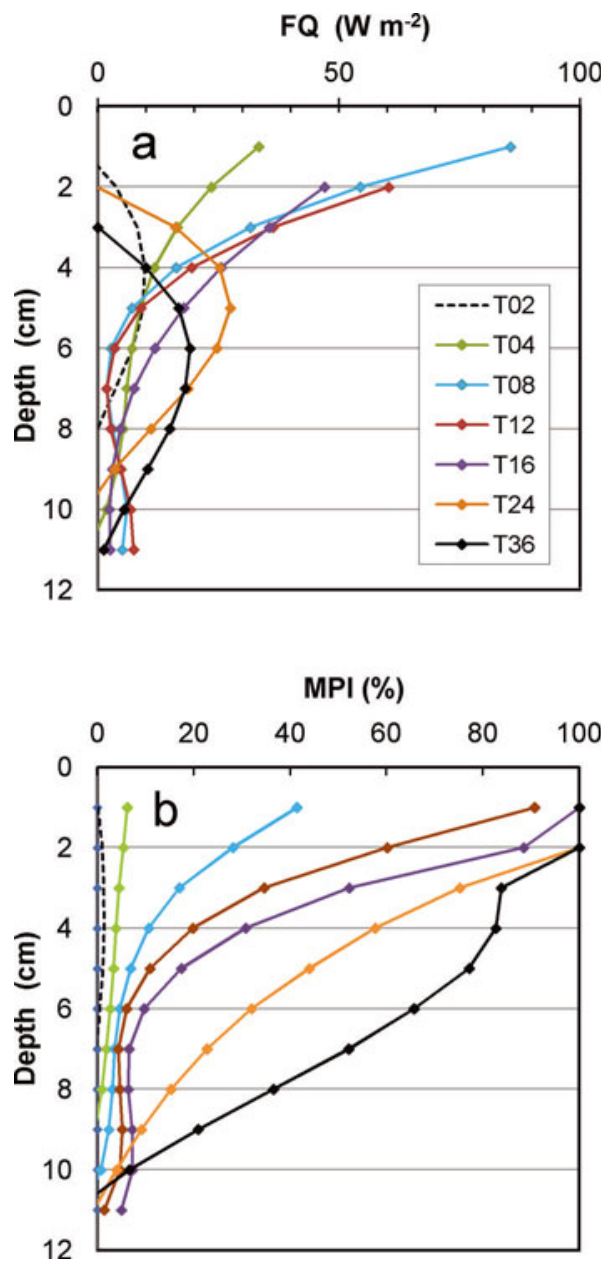

Fig. 10. Evolution of the vertical profiles after the melt onset during the experiment for (a) convergence of conductive heat flux (FQ) and (b) MPI.

structure. These processes can be represented by the time series of the total MPI and ice flexural strength (Fig. 12). Consequently, from the laboratory experiment the melting process is summarized as follows:

1. As the surface temperature increases, the C-shaped temperature profile appears and FQ reaches a maximum in the subsurface layer. But this stage lasts only for a short time and has little effect on the ice structure. (T02)

2. With the further increase of the surface temperature, the maximum FQ shifts to the surface and induces significant melting in the top $4 \mathrm{~cm}$ layer. Associated with this, the total flexural strength reduces rapidly (Fig. 12). Since the initial brine density profile is unstable, this melting induces desalinization that releases the gravitational energy in this layer. However, desalination at this stage is limited to the upper layer because of the relatively low brine volume fraction across the lower layers. ( T08)

3. Next as MPI increases in the lower layers, it promotes the flow of brine through the brine network, which leads to substantial desalinization. Since the internal melting remains high near the surface, the total flexural strength continues to be reduced. ( $\sim$ T16)

4. Through stage 3, the brine density profile becomes stable and so the desalinization becomes moderate. 


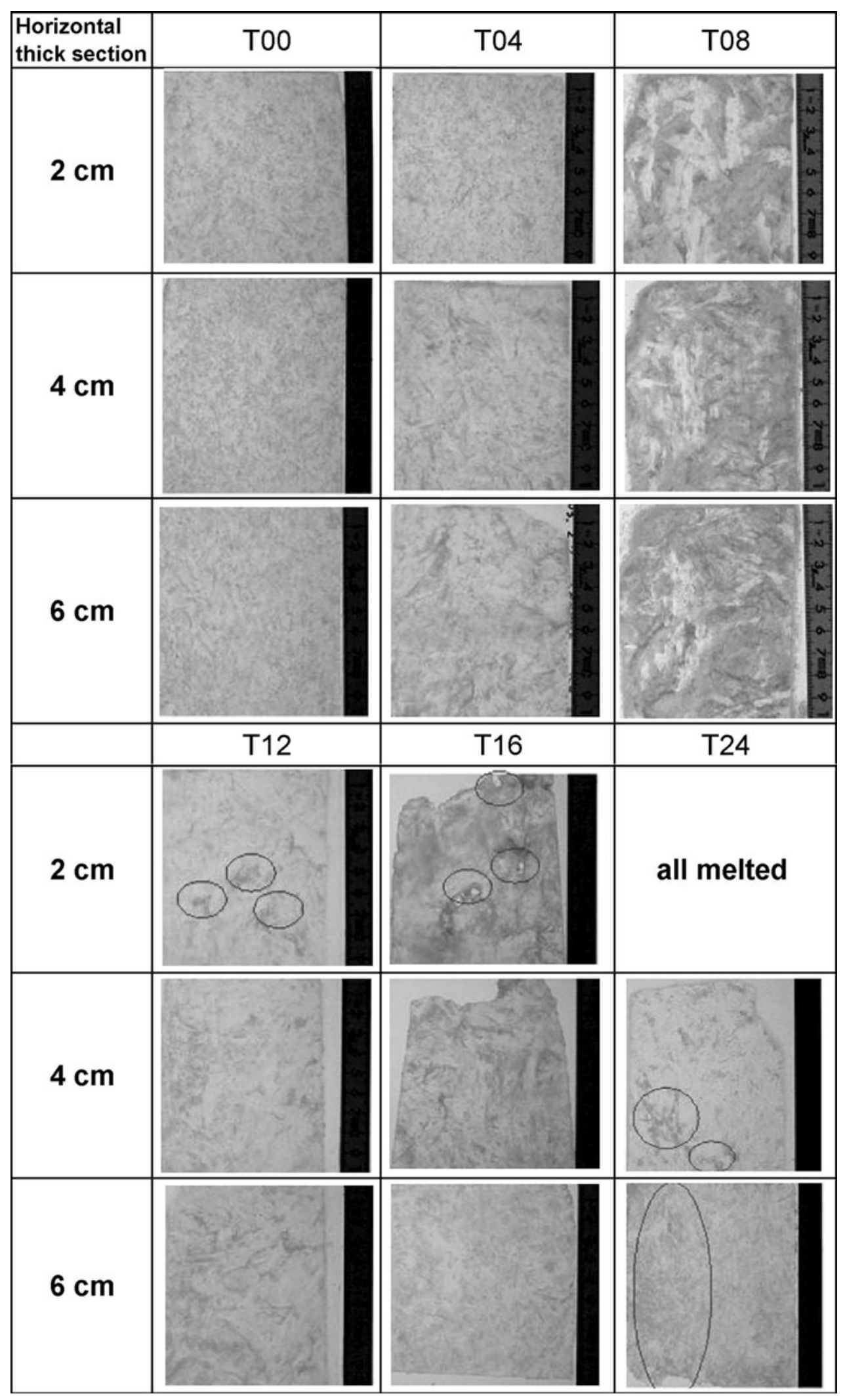

Fig. 11. Evolution of the internal ice structure observed from the horizontal thick section at depths of 2,4 and $6 \mathrm{~cm}$, showing the formation of porous structure after T12.

Concurrently, the maximum FQ shifts from the surface to the inner depth again and increases MPI at the lower depth (Fig. 12). In this way the intense internal melting migrates downward. However, at this stage the increase in total FQ is reduced and the rate of decrease in the ice flexural strength eases (Fig. 12). ( T24, T36)
Here it should be noted that the values of FQ estimated in the laboratory experiment, $0-80 \mathrm{~W} \mathrm{~m}^{-2}$, were somewhat larger than those $\left(0-50 \mathrm{~W} \mathrm{~m}^{-2}\right)$ estimated in the field observation. Therefore, to check the above result, we also carried out a repeat experiment, but at a room temperature of $3^{\circ} \mathrm{C}$ during the melting. In this case, $\mathrm{FQ}$ in 


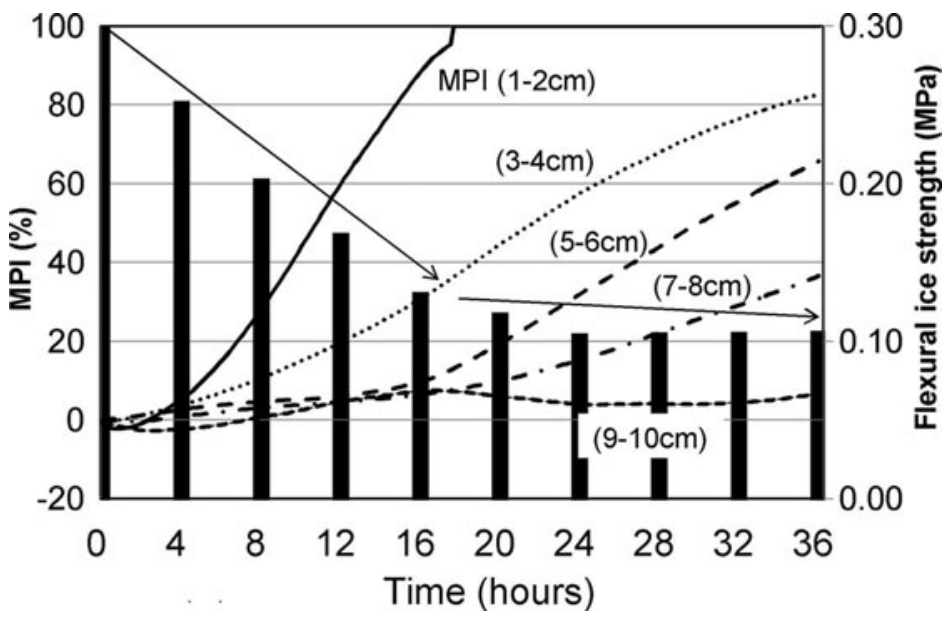

Fig. 12. Time series of MPI at each depth and total flexural ice strength, estimated from laboratory experiment.

the top layer was reduced to $10-60 \mathrm{~W} \mathrm{~m}^{-2}$, which is closer to the observational values. Thus, overall we find the above process holds true except that the progress slowed by a few hours.

Finally, we discuss the applicability to snow-covered ice. In this experiment where bare ice was used, the maximum of FQ and MPI was shown to linger for many hours at the surface at stages 2 and 3 . This is attributed mainly to the salient increase of surface ice temperature. For snow-covered ice, however, the increase in ice surface temperature is expected to be reduced due to the presence of snow (compare Fig. 3a with Fig. 5a). In this case, we infer that the value of FQ at the ice surface would be somewhat reduced and the maximum of FQ would migrate downwards faster before substantial melting occurs at the surface, as demonstrated by Tison and others (2008, fig. 5). The migration speed would depend on the duration of the warming by the external forcing. If the maximum FQ lingers at a certain depth, it would be possible that internal melting occurs intensively there, as observed by Abe (2007; Fig. 1).

\section{NUMERICAL CALCULATION}

While it was shown in the laboratory experiment that the temperature profile plays an essential role in the evolution of internal melting, there were some constraints in the experiment (e.g. that ice thickness was limited to $\sim 0.1 \mathrm{~m}$ at most and that the room temperature was kept constant). To extend the result to thicker sea ice, exposed to variable meteorological conditions, numerical modeling is required. In this section, we take the sea ice obtained in Lake Saroma from the field observation as an example and examine the progress of the internal melting through the melt season.

\section{Formulation of the model}

Since our method for calculating the heat budget, based on $M \& U$, came close to representing the evolution of sea-ice structure in both the field observation and tank experiment, we adopt the same method here. In the model, sea ice is assumed to be a horizontally uniform slab of $0.35 \mathrm{~m}$ thickness with a $0.05 \mathrm{~m}$ snow cover, following the observational result in Lake Saroma. Since this thickness value is close to that of undeformed first-year ice in the southern Sea of Okhotsk (Fukamachi and others, 2003; Toyota and others, 2004) and in the Indian sector of the Antarctic Ocean in winter (Worby and others, 2008), the result will be applicable to the wide area of the SIZ. Unlike M\&U, it is assumed that there is no snowfall, accretion or ablation of sea ice during the period. This assumption is valid because in this study we focus on a relatively short period in the melt season. The temperature within snow and sea ice is governed by the following one-dimensional heat equation:

for snow temperature

$$
\begin{aligned}
\rho_{\mathrm{s}} C_{\mathrm{s}} H_{\mathrm{s}} \frac{\partial T_{\mathrm{s}}}{\partial t}= & \left(k_{\mathrm{s}} \frac{\partial T_{\mathrm{s}}}{\partial z}\right)+\left(\mathrm{FSW}_{\text {net }}-\mathrm{FSW}_{\text {in }}+\mathrm{FLW}_{\text {in }}\right. \\
& \left.-\mathrm{FLW}_{\text {out }}+\mathrm{FSH}+\mathrm{FLH}\right) ;
\end{aligned}
$$

and for ice temperature

$$
\rho_{\mathrm{si}} C_{\mathrm{si}} \frac{\partial T_{\mathrm{si}}}{\partial t}=\frac{\partial}{\partial z}\left(k_{\mathrm{si}} \frac{\partial T_{\mathrm{si}}}{\partial z}\right)+\frac{\partial}{\partial z} \mathrm{FSW}_{\mathrm{in},}
$$

where $\rho, C, T, H$ and $k$ are the density, specific heat, temperature, thickness and thermal conductivity, respectively, and subscripts s and si denote snow and sea ice, respectively. The constant values are set to $\rho_{\mathrm{s}}=400 \mathrm{~kg} \mathrm{~m}^{-3}$, $\rho_{\mathrm{si}}=900 \mathrm{~kg} \mathrm{~m}^{-3}$ and $H_{\mathrm{s}}=0.05 \mathrm{~m}$ from the observations. The specific heat of snow, $C_{\mathrm{s}}$ is given as a function of temperature from Mellor (1977), and the specific heat of sea ice, $C_{\mathrm{si}}$, is given as a function of temperature and salinity from Ono (1968). FSW net $_{\text {is }}$ the net solar radiation absorbed at the snow surface, given by (incoming solar radiation) $\times(1-\alpha)$, where snow albedo $\alpha$ is set to 0.8 . FSW in is the solar radiation penetrating into the sea ice and expressed as $\mathrm{FSW}_{\text {net }} \exp (-\mu z)$, where $\mu$ is an extinction coefficient and is set to be $20 \mathrm{~m}^{-1}$ for snow and $3 \mathrm{~m}^{-1}$ for sea ice. FLW in is incoming longwave radiation and is estimated by $0.7855\left(1+0.2232 C^{2.75}\right) \sigma T_{\mathrm{a}}{ }^{4}$, where $C$ is the cloud fraction in tenths, $\sigma$ is the Stefan-Boltzmann constant, and $T_{\mathrm{a}}$ is air temperature, from Maykut and Church (1973). Outgoing longwave radiation $\mathrm{FLW}_{\text {out }}$ is given by $\varepsilon \sigma T_{\mathrm{s}}{ }^{4}$, where $\varepsilon$ is emissivity of snow and set to 0.99 . FLH and FSH are calculated from the same formulas that were used in the field observations. A time-step $\Delta t$ and grid spacing $\Delta z$ are set to 0.5 hour and $0.05 \mathrm{~m}$, respectively. From Eqns (6) and 

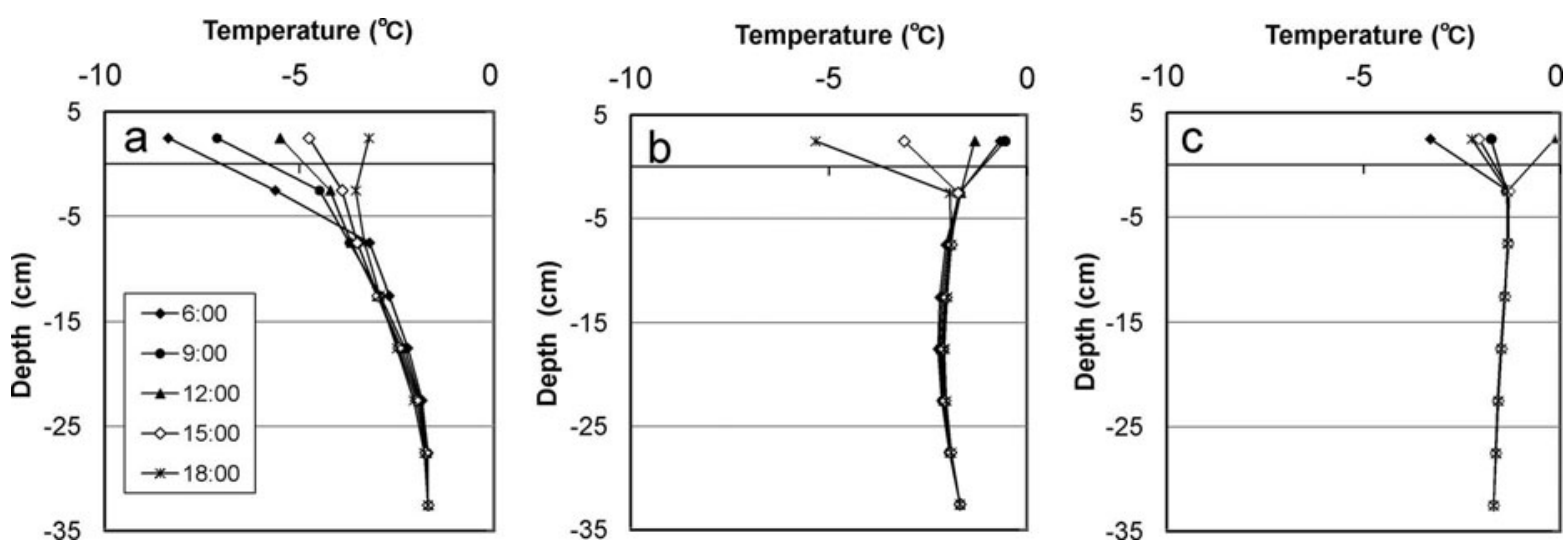

Fig. 13. Evolution of computed temperature profiles on (a) 20 February 2009, (b) 7 March 2009 and (c) 24 March 2009.

(7), the temperature at the ith layer and the $n$th time-step, $T$ $(n, i)$, is calculated by the following equations:

for snow layer

$$
\begin{aligned}
& T(n+1,1)=T(n, 1)+\left[k_{\mathrm{s}}(n, 1) \frac{T(n, 2)-T(n \pm, 1)}{\rho_{\mathrm{s}} C_{\mathrm{s}}(n, 1) H_{s}} \frac{\Delta t}{\Delta z}\right. \\
& \left.+\frac{\mathrm{FSW}_{\mathrm{net}}-\mathrm{FSW}_{\mathrm{in}}+\mathrm{FLW}_{\mathrm{in}}-\mathrm{FLW}_{\mathrm{out}}+\mathrm{FLH}+\mathrm{FSH}}{\rho_{\mathrm{s}} C_{\mathrm{s}}(n, 1) H_{\mathrm{s}}} \Delta t\right]
\end{aligned}
$$

for ice layer

$$
\begin{aligned}
T(n+1, i)= & T(n, i) \\
& +\left[k_{\mathrm{si}}(n, i+1) \frac{T(n, i+1)-T(n, i)}{\Delta z}\right. \\
& \left.-k_{\mathrm{si}}(n, i) \frac{T(n, i)-T(n, i-1)}{\Delta z}\right] \cdot \frac{1}{\rho_{\mathrm{si}} C_{\mathrm{si}}(n, i)} \frac{\Delta t}{\Delta z} \\
& +\frac{\mathrm{FSW}_{\mathrm{in}}(n, i-1 / 2)-\mathrm{FSW}_{\mathrm{in}}(n, i+1 / 2)}{\rho_{\mathrm{si}} C_{\mathrm{si}}(n, i)} \frac{\Delta t}{\Delta z}
\end{aligned}
$$

where $i=1$ and $i=2-8$ correspond to the snow layer and the ice layers, respectively. The initial temperature and salinity of sea ice were given by the values observed on-site for the $0.35 \mathrm{~m}$ thick ice at 06:00 on 20 February 2009 (courtesy of Mika Makela). We assume that the vertical profile of salinity within the ice remained unchanged over the entire period. Although in reality the salinity profile varied due to desalination processes and the tidewater flooding (Fig. 3b), it is quite difficult to predict these events, and the effect is not important because the sensitivity of physical parameters to salinity is relatively small (Ono, 1968). As for the upper boundary condition, whereas $M \& U$ calculated the surface temperature by assuming that all the fluxes are balanced at the surface, in this study $T_{\mathrm{s}}$ was determined by Eqn (8). This was necessary because our time-step ( $\Delta t=0.5$ hour) is shorter than for $M \& U$ ( $\Delta t=12$ hours), so the assumption that the fluxes are balanced may not necessarily be valid in our case. The meteorological data required to calculate the fluxes in Eqns (8) and (9) were taken from the nearest JMA stations, Tokoro for air temperature and wind speed, and Abashiri for incoming solar radiation, sea-level pressure, vapor pressure and cloud amount (see Fig. 2 for their locations). The lower boundary condition was given by $T=-1.8^{\circ} \mathrm{C}$ at the bottom. Using these data, the integration of Eqns (8) and (9) was performed from 06:00 (LST) on 20 February until 23:30 on 31 March 2009.

\section{Results and discussion}

First we validate our model by comparing it with the observational results obtained on 20 February. Figure 13a shows the diurnal variation of the temperature profiles obtained from our model. When compared with Figure 3a, it is found that there was a significant diurnal variation in the observed temperature profile, especially near the surface, and the model reproduced it well. Therefore the model results allow us to confidently examine the evolution of the temperature profile and hence melting processes within sea ice.

The time series of the observed air temperature and the modeled ice temperature at each depth are shown in Figure 14. Although a large fluctuation, including the diurnal variation, is found in air temperature (Fig. 14a), the whole period can approximately be divided into three phases: (1) the pre-melt phase (20-28 February), (2) the early melt phase (1-20 March) and (3) the mid-melt phase (21-31 March). During phase 1 , the average temperature is about $-5^{\circ} \mathrm{C}$, ranging from -10 to $0^{\circ} \mathrm{C}$, while during phase 3 the average is $\sim 0^{\circ} \mathrm{C}$, ranging from -5 to $+5^{\circ} \mathrm{C}$. Phase 2 corresponds to the transition between these two phases. The ice temperature profiles reflect the evolution of air temperature (Fig. 14b). During phase 1 the negative vertical gradient was maintained although the diurnal variation was seen near the surface. During phase 2, the negative vertical gradient was reduced and the upper layer temperature sometimes exceeded the inner temperature, suggesting the formation of the C-shaped profile. During phase 3, the temperature within the sea ice became almost homogeneous at the freezing point.

This feature is visualized by the diurnal variation of the temperature profile on a specific day in Figure 13. The temperature profiles are characterized by a negative vertical gradient with significant diurnal variation near the surface during phase 1 (Fig. 13a), the C-shaped figure with still large diurnal variation near the surface during phase 2 (Fig. 13b) and an almost homogeneous or even slightly positive gradient with reduced diurnal variation during phase 3 (Fig. 13c). The decrease in the diurnal variation of ice temperature with time is attributed mainly to the property that the specific heat of sea ice increases significantly with the increase in ice temperature (Ono, 1968). The comparison between temperature profiles at each phase suggests that, especially during the early melt season (phase 2), the convergence of conductive heat flux $\mathrm{FCl}$ plays an important role in the internal melting process. 

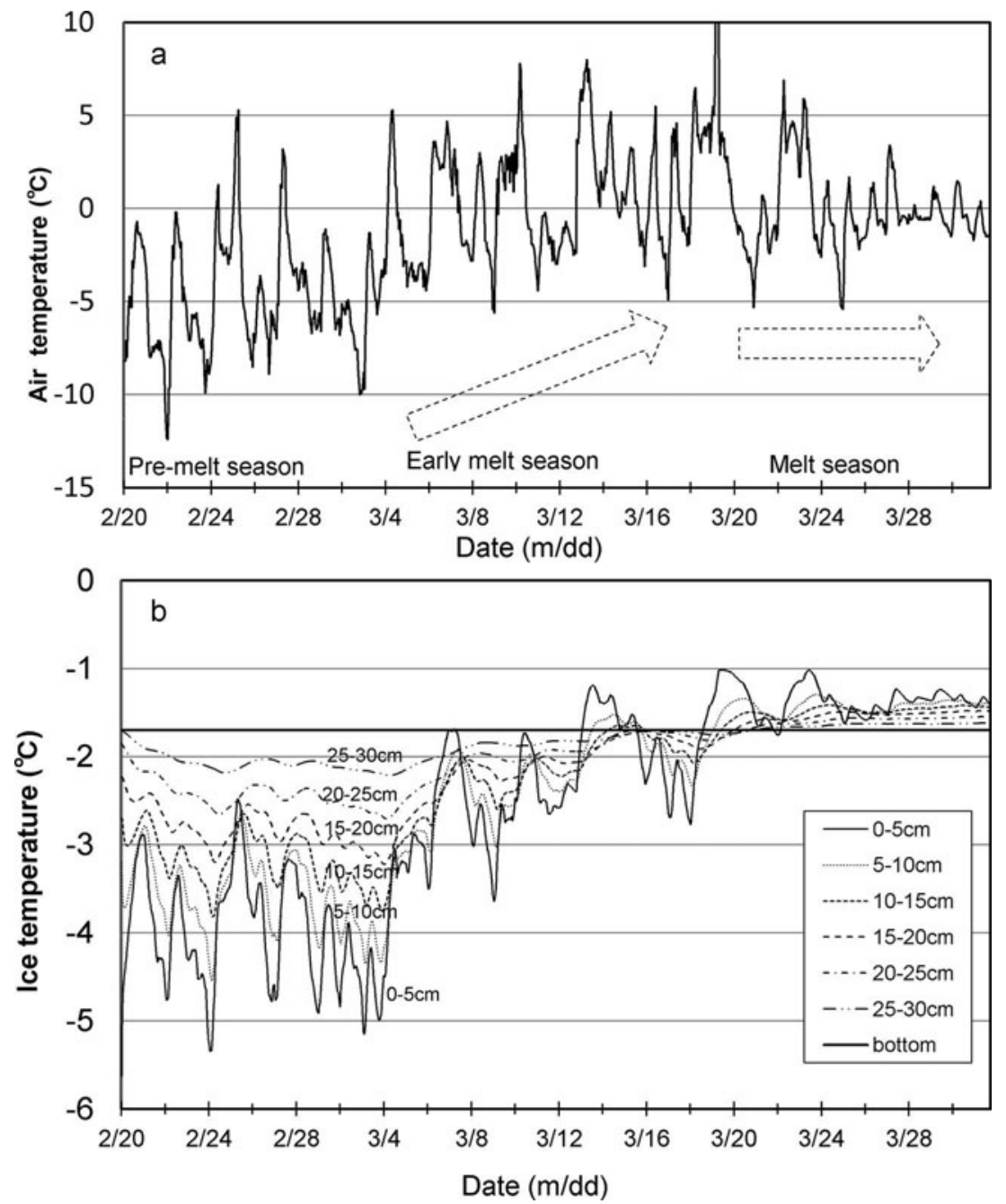

Fig. 14. Time series of (a) air temperature observed at the Tokoro JMA station, and (b) the ice temperature at each level calculated from numerical modeling. Dates are month/day in 2009.

This is confirmed by the heat budget analysis. Figure 15 shows the contribution of $\mathrm{FCl}$ and FSW at each depth, averaged for each phase. During phase 2, $\mathrm{FCl}$ dominates the warming, especially near the surface, and the contribution of FSW is much less. In this phase, as time progresses, the convergence of $\mathrm{FCl}$ gradually migrated downward, so the internal melting propagated to the lower depths. This feature contrasts with the results obtained for phases 1 and 3 . During phase 1, $\mathrm{FCl}$ instead contributes to cooling except in the surface layer (Fig. 15a), and during phase 3 the contribution of $\mathrm{FCl}$ was reduced and almost comparable with that of FSW (Fig. 15c).

Associated with the evolution of the internal melting, ice flexural strength also changed significantly. Figure 16 shows the time series of the total MPI and ice flexural strength. MPI, which remained low during phase 1 , increased significantly at all depths during phase 2. Accompanying this MPI increase was a significant decrease in the ice flexural strength. It is noticeable that, at the end of phase 2, MPI in the $15-20 \mathrm{~cm}$ layer surpassed that in the upper layer, suggesting the intense internal melting there. In phase 3, the MPI increase became moderate, so the ice flexural strength became relatively stable. This property is similar to that obtained in the tank experiment (Fig. 12).

Therefore the early melt season plays an important role in decreasing flexural ice strength, most significantly due to the characteristic C-shaped temperature profile. This is consistent with the result of Johnston (2006) in that ice strength shows a stepwise decrease according to the evolution of brine volume during the melt season.

\section{CONCLUSION}

We conducted field observations, laboratory experiments and numerical modeling to improve the understanding of melting processes of the seasonal sea ice during the early melt season. Special emphasis was placed on the evolution of the temperature profile within sea ice to examine the effect of the C-shaped temperature profile on intense internal melting, which typically occurs in this season. The evolution of conductive heat flux and its role in the heat budget were first examined quantitatively through the field observations and the tank experiments. The role of the early melt season in the melting processes was further examined by extending the period of analysis over a longer melt season through the numerical modeling. The evolution of ice flexural strength, associated with the internal melting, was also estimated. Our results are summarized as follows:

From the field observations it was found for bare ice that the intense internal melting was caused primarily by the shortwave radiation absorption (FSW) as suggested by past studies (Ishikawa and Kobayashi, 1985), whereas for 

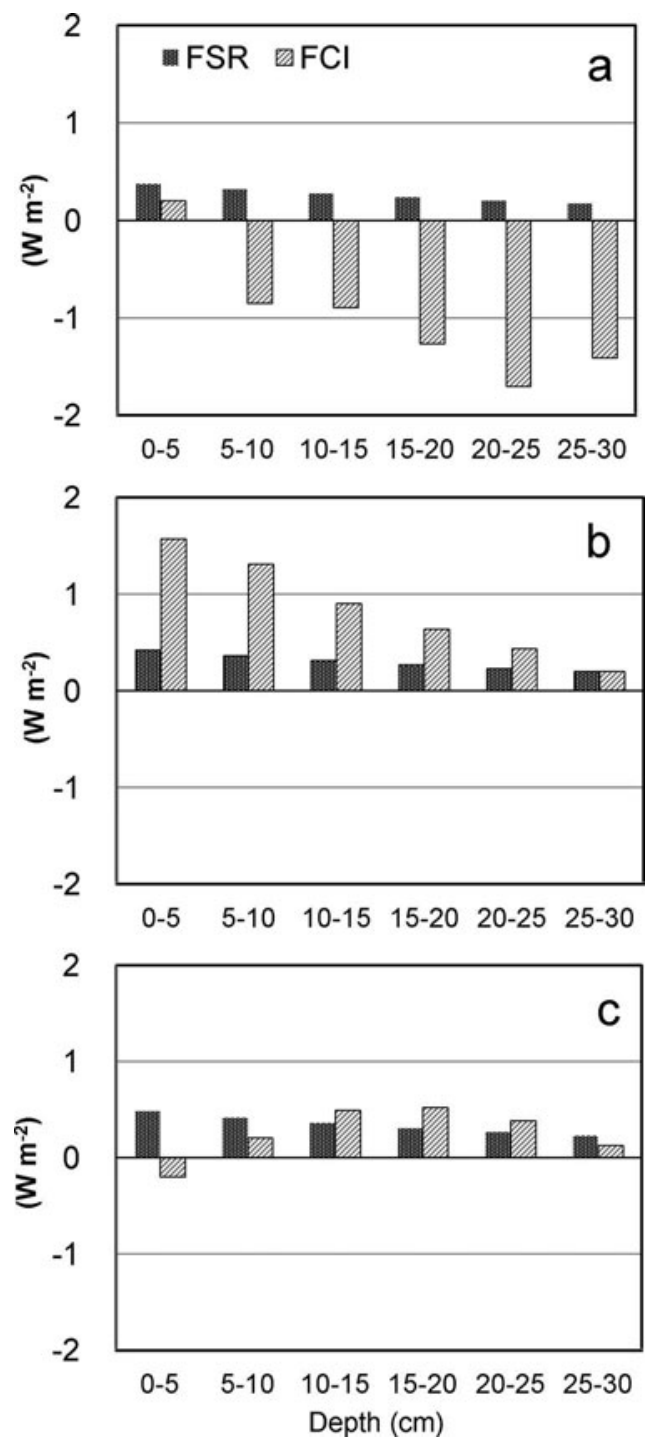

Fig. 15. The profiles of the heat budget estimated from numerical modeling, averaged for (a) phase 1 (20-28 February), (b) phase 2 (1-20 March) and (c) phase 3 (21-31 March).

snow-covered ice it was predominantly caused by the convergence of conductive heat flux $(\mathrm{FCl})$, induced by the increase of surface temperature.

From the laboratory experiments it was found that there are approximately four stages in the evolution of sea-ice structure.

1. Soon after the surface temperature begins to increase, the C-shaped temperature profile appears and FQ becomes a maximum in the subsurface layer. This stage only lasts for a short time and has little effect on the ice structure.

2. With the rapid increase in surface temperature, the maximum FQ shifts to the surface and induces significant internal melting in the top $4 \mathrm{~cm}$ layer. In association with this, the total flexural strength rapidly decreases. This also induces desalinization that releases the gravitational energy in this layer. However, desalinization is limited to the upper layer because relatively low brine volume fraction in the lower layers hampers brine drainage.

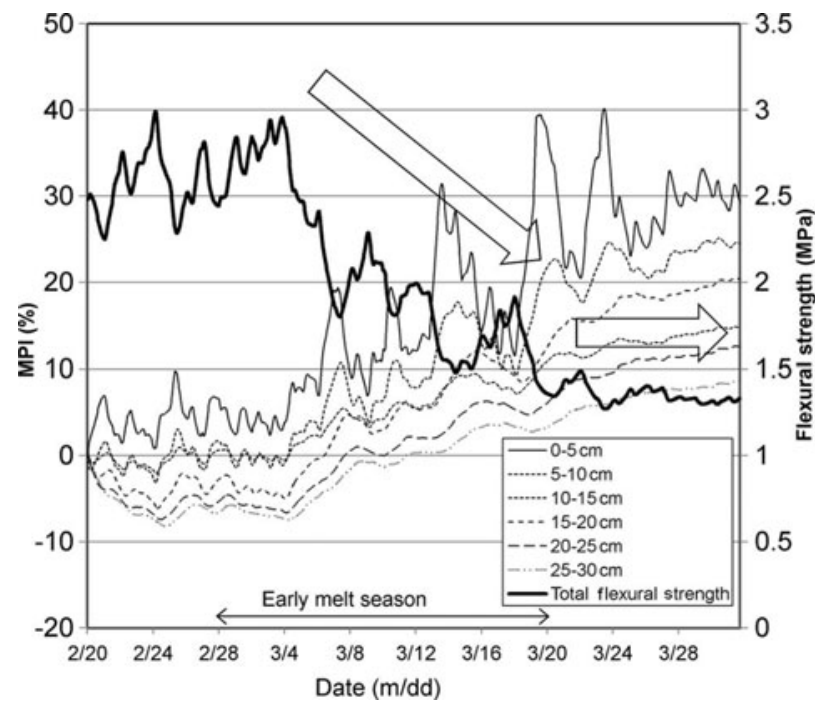

Fig. 16. Time series of MPI at each level and the total ice flexural strength, estimated from numerical modeling. Dates are month/day in 2009 .

3. As MPI increases in the lower layers, it becomes easier for brine to flow down through the brine network, leading to substantial desalinization. Conversely, since the internal melting still remains high near the surface, the total flexural strength continues to reduce.

4. The brine density profile becomes stable, so the desalinization is moderated. Additionally, the high FQ migrates downward and the total FQ decreases, leading to the decreasing rate of ice flexural strength easing.

From the numerical modeling it was confirmed that during the melt season the internal melting within snow-covered sea ice is controlled by the temperature profile rather than the solar radiation and that during the early melt season, when the C-shaped temperature profile is produced, this plays an important role in inducing intense internal melting and a drastic decrease in ice flexural strength. This result is consistent with that of Johnston (2006) in that the ice strength becomes reduced through two steps in the melt season.

This study shows that the early melt season is characterized by a drastic change in sea-ice structure, caused mainly by the evolution of the temperature profile rather than the increase in solar radiation. The decrease in ice flexural strength leads to the break-up of a sea-ice pack by waves, and promotes further melting of ice. In this way the evolution of sea-ice structure during the early melt season is closely related to the retreat of sea-ice extent. Therefore, we believe that our result can be applied to the melting process on a global scale. Further investigation of the wave-ice interaction to understand the whole melting process, including the evolution of ice properties, will be required in the future.

\section{ACKNOWLEDGEMENTS}

We thank Christian Haas, Keiichirou Ohshima, Yasushi Fujiyoshi, Kunio Shirasawa and Yuji lijima for their valuable comments and suggestions, and Guy Williams for the proofreading. This work was supported financially by KAKENHI (21510002) of the Japan Society for the Promotion of Science. 


\section{REFERENCES}

Abe M (2007) A study on seasonal evolution of the structural properties of brine drainage channel within sea ice. (Master's thesis, Hokkaido University)

Ackley SF, Geiger CA, King JC, Hunke EC and Comiso J (2001) The Ronne polynya of 1997/98: observations of air-ice-ocean interaction. Ann. Glaciol., 33, 425-429

Ackley SF, Lewis MJ, Fritsen $\mathrm{CH}$ and Xie H (2008) Internal melting in Antarctic sea ice: development of 'gap layers'. Geophys. Res. Lett., 35(11), L11503 (doi: 10.1029/2008GL03364)

Andreas EL and Makshtas AP (1985) Energy exchange over Antarctic sea ice in the spring. J. Geophys. Res., 90(C4), 7199-7212

Bennetts LG, Peter MA, Squire VA and Meylan MH (2010) A threedimensional model of wave attenuation in the marginal ice zone. J. Geophys. Res., 115(C12), C12043 (doi: 10.1029/ 2009JC005982)

Comiso JC (2010) Variability and trends of the global sea ice cover. In Thomas DN and Dieckmann GS eds. Sea ice. WileyBlackwell, Oxford

Cox GFN and Weeks WF (1983) Equations for determining the gas and brine volumes in sea-ice samples. J. Glaciol., 29(102), 306-316

Frankenstein G and Garner R (1967) Equations for determining the brine volume of sea ice from $-0.5^{\circ} \mathrm{C}$ to $-22.9^{\circ} \mathrm{C}$. J. Glaciol. 6(48), 943-944

Fukamachi Y, Mizuta G, Ohshima KI, Melling H, Fissel D and Wakatsuchi M (2003) Variability of sea-ice draft off Hokkaido in the Sea of Okhotsk revealed by a moored ice-profiling sonar in winter of 1999. Geophys. Res. Lett., 30(7), 1376 (doi: 10.1029/ 2002GL016197)

Golden KM, Ackley SF and Lytle VI (1998) The percolation phase transition in sea ice. Science, 282(5397), 2238-2241

Haas C, Thomas DN and Bareiss J (2001) Surface properties and processes of perennial Antarctic sea ice in summer. J. Glaciol., 47(159), 613-625

Ishikawa $\mathrm{N}$ and Kobayashi S (1985) On the internal melting phenomenon (puddle formation) in fast sea ice, East Antarctica. Ann. Glaciol., 6, 138-141

Johnston M (2006) A comparison of physical properties and strength of decaying first-year ice in the Arctic and sub-Arctic. Ann. Glaciol., 44, 154-162

Jouzel J and Souchez RA (1982) Melting-refreezing at the glacier sole and the isotopic composition of the ice. J. Glaciol., 28(98), 35-42

Kojima S, Kawamura T and Enomoto H (2005) Preliminary study of the transition of sea ice during the melting process. Polar Meteorol. Glaciol., 19, 108-119

Maykut GA (1978) Energy exchange over young sea ice in the central Arctic. J. Geophys. Res., 83(C7), 3646-3658

Maykut GA (1986) The surface heat and mass balance. In Untersteiner $\mathrm{N}$ ed. Geophysics of sea ice. Plenum Press, London, 395-463 (NATO ASI Series B: Physics 146)

Maykut GA and Church PE (1973) Radiation climate of Barrow, Alaska, 1962-66. J. Appl. Meteorol., 12(4), 620-628

Maykut GA and Untersteiner N (1971) Some results from a timedependent thermodynamic model of sea ice. J. Geophys. Res., 76(6), 1550-1575
Mellor M (1977) Engineering properties of snow. J. Glaciol., 19(81), 15-66

Nakawo M and Sinha NK (1981) Growth rate and salinity profile of first-year sea ice in the High Arctic. J. Glaciol., 27(96), 315-330

Nihashi S and Cavalieri DJ (2006) Observational evidence of a hemispheric-wide ice-ocean albedo feedback effect on Antarctic sea-ice decay. J. Geophys. Res., 111(C12), C12001 (doi: 10.1029/2005JC003447)

Ono N (1968) Thermal properties of sea ice. IV. Thermal constants of sea ice. Low Temp. Sci., Ser. A 26, 329-349 [In Japanese]

Perovich DK (1998) The optical properties of sea ice. In Leppäranta $\mathrm{M}$ ed. Physics of ice-covered seas. University of Helsinki Press, Helsinki, 195-230

Perovich DK, Elder BC and Richter-Menge JA (1997) Observations of the annual cycle of sea ice temperature and mass balance. Geophys. Res. Lett., 24(5), 555-558

Perovich DK, Light B, Eicken H, Jones KF, Runciman K and Nghiem SV (2007) Increasing solar heating of the Arctic Ocean and adjacent seas, 1979-2005: attribution and role in the ice-albedo feedback. Geophys. Res. Lett., 34(19), L19505 (doi: 10.1029/ 2007GL031480)

Petrich C and Eicken H (2009) Growth, structure and properties of sea ice. In Thomas DN and Dieckmann GS eds. Sea ice. WileyBlackwell, Chichester, 23-77

Prinsenberg SJ and Peterson IK (2011) Observing regional-scale pack-ice decay processes with helicopter-borne sensors and moored upward-looking sonars. Ann. Glaciol., 52(57 Pt 1), 35-42

Shirasawa K, Fujiyoshi Y and Maekawa K (2002) Sea ice and hydrological environments of Lake Saroma. Kaiyo Monthly Extra issue 30, 50-61 [In Japanese]

Shokr ME and Barber DG (1994) Temporal evolution of physical and dielectrical properties of sea ice and snow during the early melt season: observations from SIMS '90 experiment. J. Glaciol., 40(134), 16-30

Steele M (1992) Sea ice melting and floe geometry in a simple iceocean model. J. Geophys. Res., 97(C11), 17 729-17 738

Timco GW and O'Brien S (1994) Flexural strength equation for sea ice. Cold Reg. Sci. Technol., 22(3), 285-298

Tison J-L and 8 others (2008) Temporal evolution of decaying summer first-year sea ice in the Western Weddell Sea, Antarctica. Deep-Sea Res. II, 55(8-9), 975-987

Toyota T, Kawamura T, Ohshima KI, Shimoda $\mathrm{H}$ and Wakatsuchi M (2004) Thickness distribution, texture and stratigraphy, and a simple probabilistic model for dynamical thickening of sea ice in the southern Sea of Okhotsk. J. Geophys. Res., 109(C6), C06001 (doi: 10.1029/2003JC002090)

Toyota T, Haas C and Tamura T (2011) Size distribution and shape properties of relatively small sea-ice floes in the Antarctic marginal ice zone in late winter. Deep-Sea Res. II, 58(9-10), 1182-1193

Worby AP, Geiger CA, Paget MJ, Van Woert ML, Ackley SF and Deliberty TL (2008) Thickness distribution of Antarctic sea ice. J. Geophys. Res., 113(C5), C05S92 (doi: 10.1029/ 2007JC004254)

Yen YC (1981) Review of thermal properties of snow, ice and sea ice. CRREL Res. Rep. 81-10

MS received 19 July 2011 and accepted in revised form 14 October 2011 